\title{
ALTO DA CERCA (VALPAÇOS, PORTUGAL): UM ASSENTAMENTO MILITAR ROMANO NA SERRA DA PADRELA E SUA RELAÇÃO COM O DISTRITO MINEIRO DE TRESMINAS
}

\author{
JOÃO FONTE ${ }^{(1)} \&$ JOSÉ MANUEL COSTA-GARCÍA ${ }^{(2)}$
}

Resumo:

\begin{abstract}
Pretendemos com este trabalho dar a conhecer um possível assentamento militar romano localizado na vertente Oriental da serra da Padrela: o Alto da Cerca (Valpaços, Portugal). O uso de uma metodologia não-invasiva permitiunos caracterizar arqueologicamente este sítio e diferenciá-lo em relação à rede de povoamento local. Tendo em consideração que o exército romano estaria directamente envolvido em tarefas de controlo e proteção das zonas mineiras, mas também com questões logísticas e técnico-administrativas de planificação, administração e organização territorial, procuramos contextualizar este assentamento em relação ao distrito mineiro romano de Tresminas.
\end{abstract}

Palavras-chave: Exército Romano, fotogrametria, padrões de assentamento, povoados fortificados da Idade do Ferro, mineração aurífera romana.

Abstract:

Alto da Cerca (Valpaços, Portugal): a Roman military settlement in the Padrela Mountain and its relation to the mining district of Tresminas

In this work, we study a possible Roman military settlement located on the eastern slope of the Padrela Mountain, named Alto da Cerca (Valpaços, Portugal). The use of a non-invasive methodology allowed us to characterise the site archaeologically and to differentiate it in relation to the local settlement network. Considering that the Roman army was directly involved in control tasks and protection of mining areas, but also in logistical issues and technical and administrative planning, as well as administration and territorial organization, we seek to contextualize the settlement in relation to the Roman mining district of Tresminas.

Keywords: Roman Army, photogrammetry, settlement patterns, Iron Age hillforts, Roman gold mining.

\section{ARQUEOLOGIA MILITAR ROMANA NO NOROESTE PENINSULAR ${ }^{1}$}

O estudo da presença militar romana no Noroeste Peninsular conta já com uma larga tradição de investigação (e.g. GARCíA Y BELlidO 1961; LE-RouX 1982). No que ao território português diz respeito, esta linha de trabalho encontrase ainda num estado embrionário, tendo-se centrado até à data mais na leitura dos textos clássicos e não tanto na evidência arqueológica (FABIÃO 2007).

Nos últimos anos têm sido identificados na região das Astúrias e Cantábria um conjunto de acampamentos militares romanos directamente relacionados com o Bellum Asturicum et Cantabricum (DIDIERJEAN 2008; DIDIERJEAN et al. 2014; MENÉNDEZ-BLANCO et al. 2011, 2012, 2013a; PERALTA-LABRADOR 2011), mas também com o controlo do território depois da conquista e o início das explorações mineiras (GONZÁLEZÁlVAREZ et al. 2008), tendo-se recorrido a uma metodologia de prospecção de baixo custo para localizar estes sítios (MENÉNDEZ-BLANCO et al. 2013b). Com o advento da fotografia aérea (DEL
OLMO MARTíN 1995; GARCÍA-MERINO 1996; LOEWINSOHN 1965; SÁNCHEZ-PALENCIA 1986) e, mais recentemente, do LiDAR aéreo (COSTA-GARCÍA et al. 2015; COSTA-GARCÍA 2015; GAGO-MARIÑO \& FERNÁNDEZ-MALDE 2015), especialmente eficaz na deteção de estruturas arqueológicas em áreas arborizadas ou de vegetação densa, a disciplina assistiu a um grande impulso.

Contudo, a presença efetiva do exército romano no Noroeste Peninsular, em particular na zona exterior ao território onde tiveram lugar as guerras Astur-Cantábricas, continua ainda a ser uma verdadeira incógnita. No território galaico não existiam, aparentemente, acampamentos como os da região das Astúrias e Cantábria. A Cidadela (Sobrado dos Monxes, A Coruña) e Aquae Querquennae (Bande, Ourense), posteriores ao processo de conquista do Noroeste, são os assentamentos militares romanos melhor conhecidos até à data (COSTA-GARCÍA, 2013). Este cenário está a começar a mudar, graças a novas descobertas produzidas na zona (COSTA-GARCÍA et al. 2015), mas a ideia mais difundida é que o território galaico bracarense teria desempenhado um papel de retaguar-

(1) Instituto de Ciencias del Patrimonio (Incipit), Consejo Superior de Investigaciones Científicas (CSIC); Centro de Investigação em Ciências Geo-Espaciais (CICGE), Universidade do Porto. E-mail: joaofonte@gmail.com

(2) Universidade de Santiago de Compostela (USC) - Vrije Universiteit Amsterdam (VU). E-mail: josemanuel.costa@usc.es /josem.costagarcia@gmail.com ${ }^{1}$ Este trabalho insere-se no âmbito da investigação doutoral do primeiro signatário recentemente defendida na Universidade de Santiago de Compostela (FONTE 2015). 
da, base de operações e de aprovisionamento relativamente às guerras de conquista do Norte Peninsular (MoRILlo-CERdÁn 2002, 2014). Por outro lado, não se pode subestimar o papel fundamental do exército romano em relação a um momento inicial de ocupação, organização e exploração do território e dos seus recursos naturais, uma vez que o controlo efetivo de um território antecede, logicamente, o seu aproveitamento.

Em relação especificamente às zonas mineiras, o exército romano teve certamente um papel bastante importante no processo de prospeção e abertura das minas e de implementação das infraestruturas necessárias, tanto por razões técnicas como administrativas (SASTRE et al. 2010). Alguns acampamentos romanos podem-se associar diretamente a zonas mineiras, tais como o de Lomba do Canho (NunEs et al. 1988), o de VALDEMEDA (SÁNCHEZ-PALENCIA 1986) e também o possível recinto documentado na zona de PenamacorMeimoa (SÁNCHEZ-PALENCIA \& PÉREZ-GARCÍA 2005: 285), sendo que estes dois últimos foram mesmo alterados pelo próprio avanço dos trabalhos mineiros.

Neste sentido, consideramos que o assentamento do Alto da Cerca se poderá relacionar com a presença do exército romano em ligação direta com a zona mineira de Tresminas, problemática que iremos de seguida discutir.

\section{MATERIAL E MÉTODOS}

Para a análise morfológica e definição da planta do recinto do Alto da Cerca utilizamos diversos produtos cartográficos. Por um lado, interpolamos um modelo digital de terreno (MDT) com $5 \mathrm{~m}$ de resolução a partir das curvas de nível e pontos cotados da cartografia 1:10.000 do concelho de Valpaços ${ }^{2}$. Por outro, fizemos também uso das imagens de satélite de Google Inc. (07/11/2002, 30/10/2006, 19/10/2009, 07/04/2010, 18/06/2011 e 31/08/2013) e Bing Maps (2015) e das ortofotos digitais de Portugal com resolução de $50 \mathrm{~cm}$ (ORTOS_DGRF_2004_06) disponibilizadas pela Direção-Geral do Território (DGT) através de web map service (WMS), bem como das fotografias aéreas históricas disponíveis, que restituímos fotogrametricamente.

As fotografias aéreas históricas, obtidas nas décadas de $40^{3}$ e $50^{4}$ do século XX, foram digitalizadas pelo Instituto Geográfico do Exército (IGeoE) num scanner fotogramétrico de alta resolução (1200 dpi). O programa Photoscan ${ }^{5}$ foi utili- zado no seu processamento para a extracção automática de uma nuvem de pontos e um modelo tridimensional do terreno, assim como para a montagem de um mosaico de orto-imagens georreferenciadas (VERHOEVEN et al. 2012). Dado que este programa se destina a processar fotos obtidas por câmaras digitais, foi necessário fazer um préprocessamento das fotos aéreas, para que todas tenham a mesma dimensão em número de pixéis e o mesmo alinhamento em relação ao sistema ótico da câmara. Para tal, tomou-se uma das fotos como referência e utilizaram-se as suas marcas fiduciais para alinhar as restantes fotos com a de referência. Foram então recortadas e reamostradas de forma a adquirirem a dimensão da foto de referência.

O processamento no Photoscan passa pela identificação automática de pontos comuns entre as diferentes fotos, determinando-se assim a orientação relativa entre elas. Através da utilização de pontos de controlo identificados em fotografias aéreas atuais foi possível georreferenciar o bloco de fotos. Apesar da diferença temporal entre fotos antigas e atuais identificaram-se sobretudo muros limite de campos agrícolas que não sofreram alterações dado tratar-se de uma zona rural. As cotas foram obtidas a partir do MDT com $5 \mathrm{~m}$ de resolução referido anteriormente.

O passo seguinte consistiu na geração de uma nuvem densa de pontos comuns, para os quais são calculadas coordenadas tridimensionais, dando origem a um modelo digital de superfície (MDS). $\mathrm{O}$ passo final refere-se à correção geométrica de todas as deformações das fotos, usando esse modelo tridimensional (MDS), e na construção de um mosaico contínuo de todas as fotos tratadas. O modelo tridimensional e o mosaico encontram-se corretamente georreferenciados num sistema de coordenadas comum, podendo por isso ser visualizados corretamente sobrepostos num software de SIG.

Este processo de restituição fotogramétrica digital permitiu-nos, assim, construir um MDS e produzir um mosaico de ortoimagens ${ }^{6}$ que utilizamos de forma integrada com a restante informação geográfica disponível na fotointerpretação e digitalização do conjunto de estruturas topográficas positivas e negativas do recinto, que seguidamente foram discriminadas e classificadas de acordo com critérios morfo-tipológicos. Todo este trabalho foi devidamente complementado e validado com observações feitas em campo, onde pudemos avaliar e documentar in situ a existência das estruturas arqueológicas identificadas previamente na infor-

\footnotetext{
${ }_{3}^{2}$ Esta cartografia foi-nos gentilmente cedida pela Câmara Municipal de Valpaços, a quem agradecemos.

${ }^{3}$ A primeira empresa de fotogrametria existente em Portugal, denominada Sociedade Portuguesa de Levantamentos Aéreos Limitada - SPLAL, encarregou-se entre 1937 e 1952 dos primeiros voos nacionais de mapeamento para produção cartográfica (REDWEIK et al. 2010); as fotos têm uma escala aproximada de 1:16.000 e um formato de $18 \mathrm{~cm}$ x $18 \mathrm{~cm}$, datando nesta zona de 1948. Utilizamos 4 fotos com sobreposição do voo SPLAL.

${ }^{4}$ United States Air Force (USAF) (PÉreZ-ÁLvAREZ et al. 2014); as fotos têm uma escala aproximada de 1:26.000 e um formato de $23 \mathrm{~cm} \times 23 \mathrm{~cm}$, datando nesta zona de 1958. Utilizamos 2 fotos com sobreposição do voo USAF.

${ }_{6}^{5}$ AgiSoft PhotoScan Professional Edition (version 1.2.1, build 2278, 64 bit).

${ }^{6}$ MDS com $2 \mathrm{~m}$ e mosaico de ortoimagens com $0,3 \mathrm{~m}$ de resolução espacial. Finalmente optamos antes por trabalhar com os modelos extraídos a partir das fotos do voo SPLAL pois ao terem uma melhor escala conseguimos obter melhores resultados no processamento fotogramétrico.
} 
mação digital, bem como avaliar o seu estado de conservação.

\section{O RECINTO DE ALTO DA CERCA}

\subsection{Evidências estruturais}

O assentamento do Alto da $\mathrm{Cerca}^{7}$ conhecido como o Côro pelos habitantes da zonasitua-se dentro dos limites da freguesia de Padrela e Tazém (concelho de Valpaços, distrito de Vila Real), a Norte da zona mineira de Tresminas, esta última já no concelho de Vila Pouca de Aguiar. Localiza-se numa zona planáltica na vertente Oriental da serra da Padrela, na transição entre o patamar mais elevado da serra e o planalto de Carrazeda de Montenegro, num amplo mas pouco destacado relevo em esporão (985 metros de altitude máxima) sobranceiro a duas pequenas ribeiras que vão desaguar ao rio de Curros e que o rodeiam pelos lados Oeste, Norte e Leste (Fig. 1). Isto reforça consideravelmente as suas condições naturais de defesa, dado que as encostas do esporão são suaves e pouco elevadas, excetuando do lado Norte. O sítio foi já previamente referenciado por Francisco Sande Lemos (1993 II: 548-549, sítio ${ }^{\circ}$ 886), Ricardo Teixeira (1996: 110, sítio $\mathrm{n}^{\circ} 722$ ) e por Adérito Medeiros Freitas (2001: 239-242), todos coincidindo no facto de se tratar de um povoado com umas características bastante particulares, apesar de todos o classificarem, embora com as devidas reservas, como um povoado fortificado da Idade do Ferro.

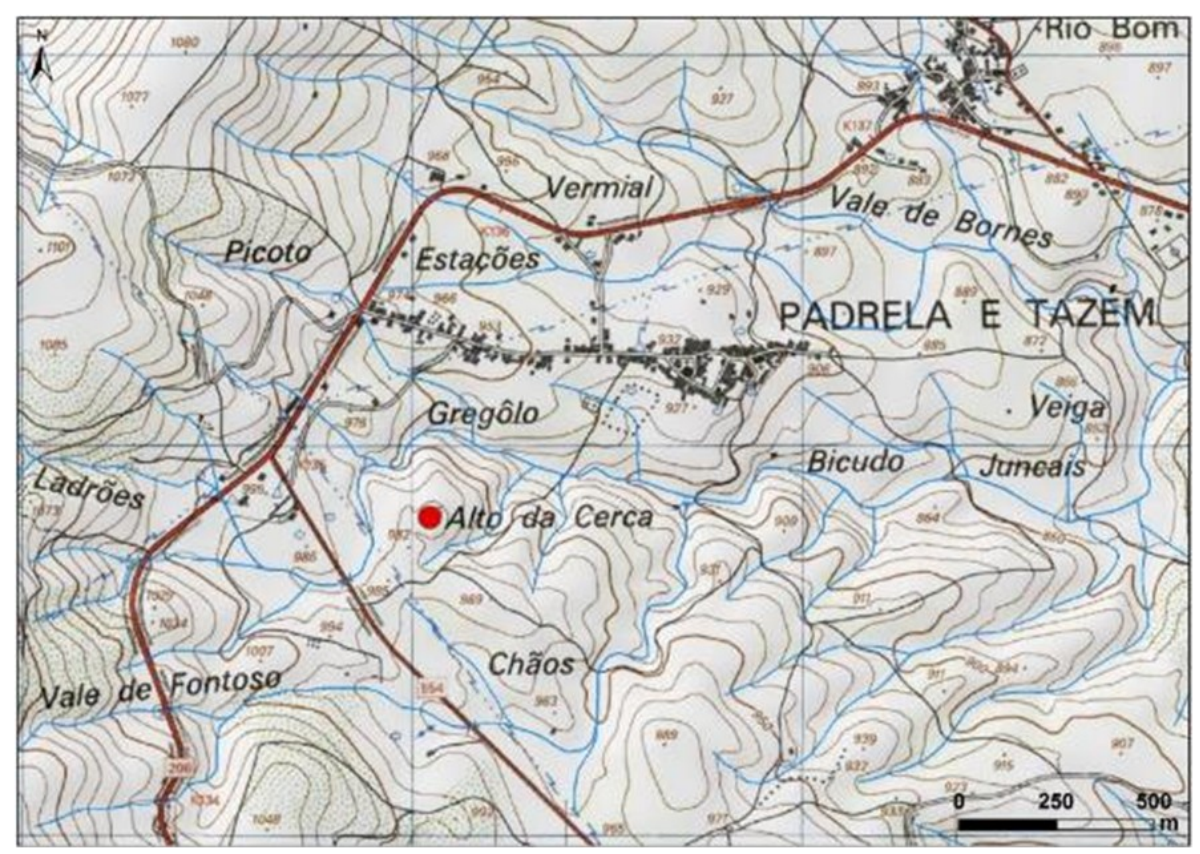

Fig. 1. Localização do Alto da Cerca na Carta Militar de Portugal à escala 1:25.000 do IGeoE, série M888, folha $n^{\circ} 61,2^{a}$ edição.

Fig. 1. Location of Alto da Cerca. Military Map of Portugal, scale 1/25.000, from the Army Geographical Institute, M888 series, $\mathrm{n}^{\circ} 61$, 2nd edition.

São vários os motivos que dificultam a reconstrução da planta do assentamento. O parcelamento e a exploração agrícola da zona alteraram significativamente a morfologia do sítio. Deve também ter-se em conta a densa vegetação que pontualmente impede o reconhecimento de algumas estruturas. O recurso à fotografia aérea histórica (SPLAL/USAF) resultou, neste sentido, de vital importância. Todavia, já aqui se pode apreciar a profunda erosão do setor Este do assentamento, algo que tivemos também ocasião de comprovar no terreno (Fig. 2 e 3 ).

Assim, o assentamento apresenta uma planta poligonal, com esquinas arredondadas e uma extensão que poderia estabelecer-se entre os dois e os três há (Fig. 4 e 5). Apesar da espessa vegetação que cobre uma grande parte do seu percurso, um marcado fosso permite apreciar sobre o terreno a integridade do recinto. Ainda assim, a sua fatura e as suas dimensões apresentam algumas variações em diferentes sectores do perímetro, o que parece indicar um aproveitamento diferenciado do terreno natural com uma finalidade defensiva. O lado Sul do esporão é, a priori, a zona mais acessível, pelo que não é de estranhar que o fosso tenha aqui o seu aspeto mais massivo. O lugar escolhido para o seu traçado tampouco é causal, pois corta uma pequena planície e cria um desnível que reforça a pendente

${ }^{7}$ Portal do Arqueólogo, CNS (Código Nacional de Sítio) 13237. 
natural ascendente em direcção ao interior do recinto. No entanto, a colina foi parcialmente cortada e aplanada, criando a sensação de que existiam neste sector dois taludes defensivos, tal como é referido por diversos autores (FREITAS, 2001 240; LEMOS 1993 II: 548-549; TEIXEIRA 1996: 110) (Fig. 6). A fotografia histórica evidencia que esta situação não é recente, mas desconhecemos se essa solução se corresponde com a morfologia original do recinto ou se é antes resultado da actividade agrícola posterior. Além disso, enquanto o fosso apresenta aqui a sua maior largura e profundidade $(15,5 \times 6 \mathrm{~m})$, consideramos que o seu estado de conservação atual não é representativo da sua fatura original. Ao ter sido aberto na terra, com o passar do tempo os taludes foram-se desmoronando devido à erosão e à escorrência de água.

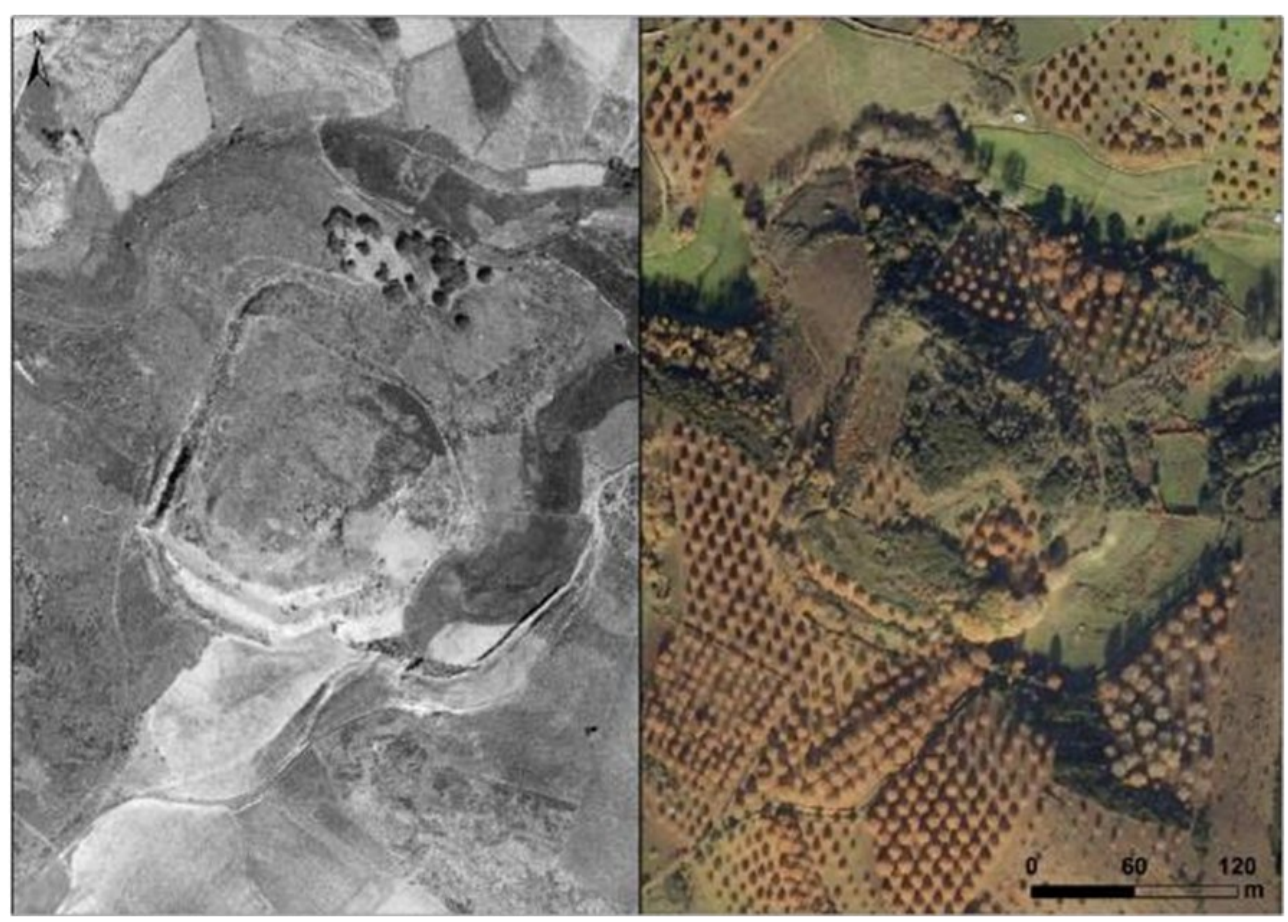

Fig. 2. Alto da Cerca na ortofoto do voo SPLAL de 1948 (à esquerda) e em ortofoto actual (ORTOS_DGRF_2004_06) (à direita).

Fig. 2. Orthophotos of Alto da Cerca: SPLAL 1948 flight (left) and DGRF 2004-2006 (ORTOS_DGRF_2004_06) (right).

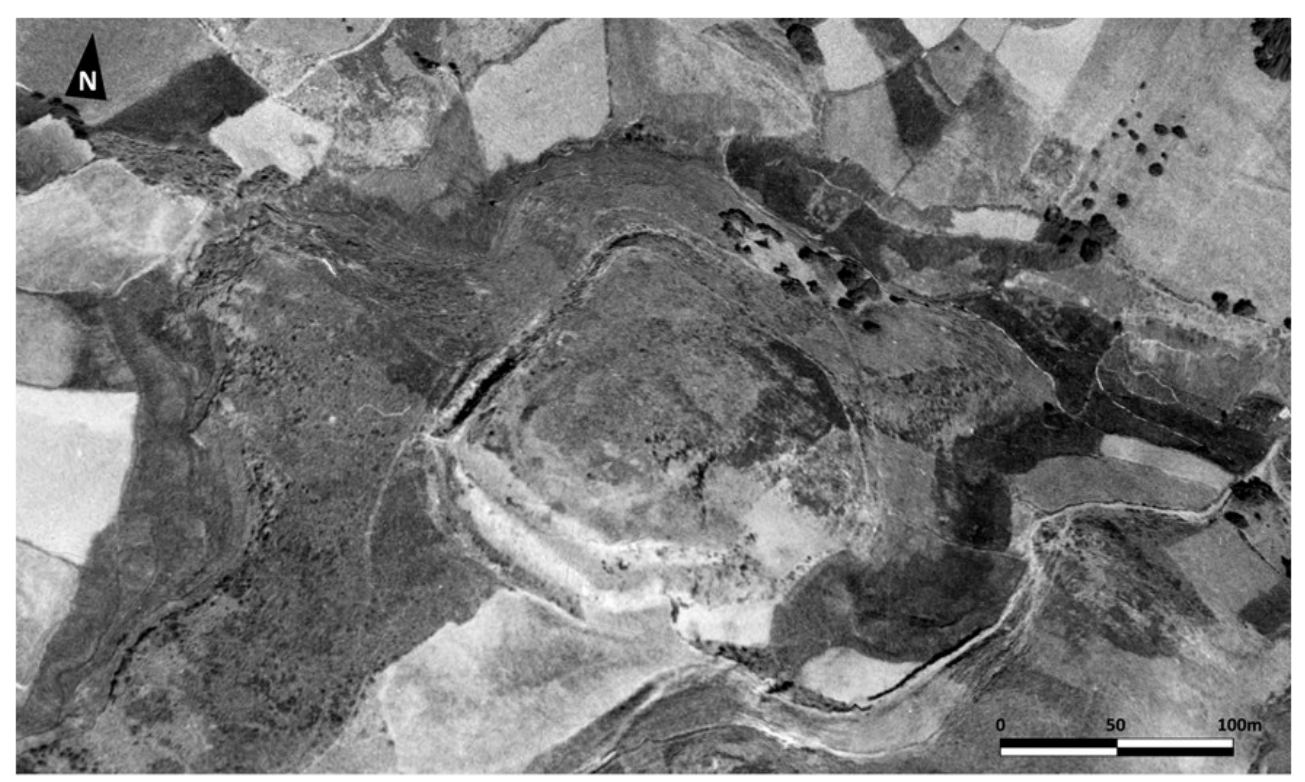

Fig. 3. Modelo 3D do Alto da Cerca com a ortofoto sobreposta ao MDS.

Fig. 3. Alto da Cerca 3D model with the orthophoto superimposed to the DSM. 


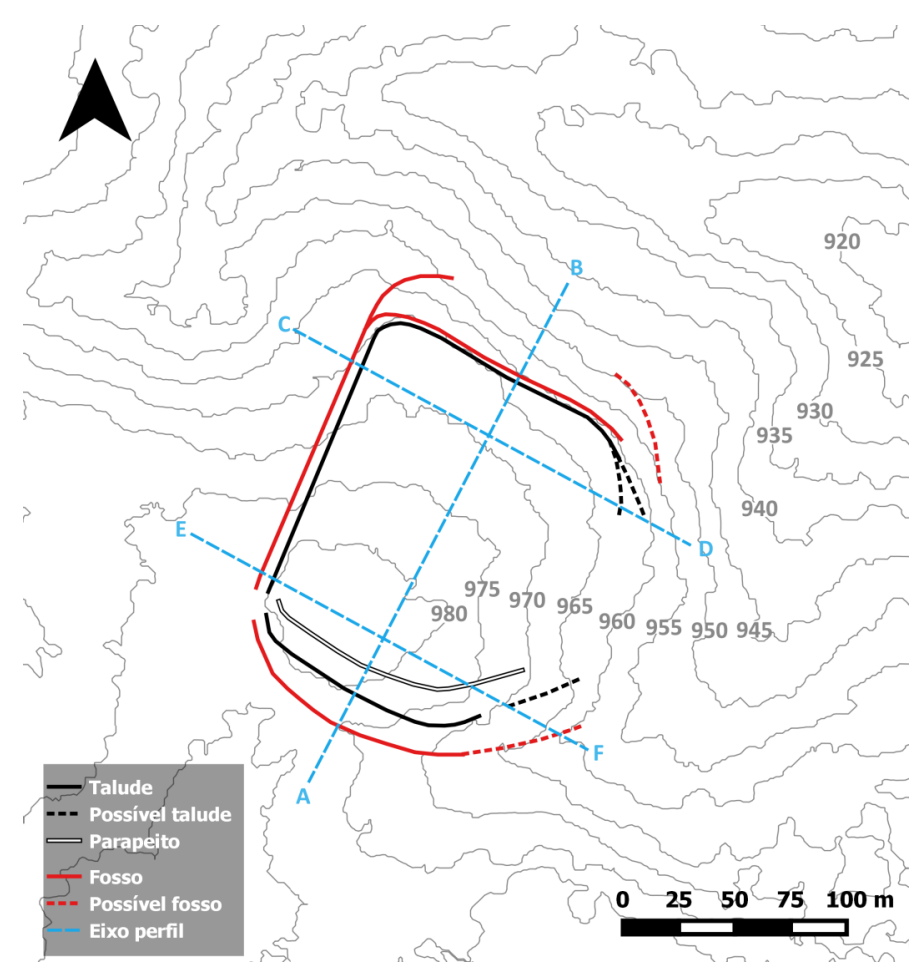

Fig. 4. Planta topográfica do Alto da Cerca.

Fig. 4. Alto da Cerca topographical plan.

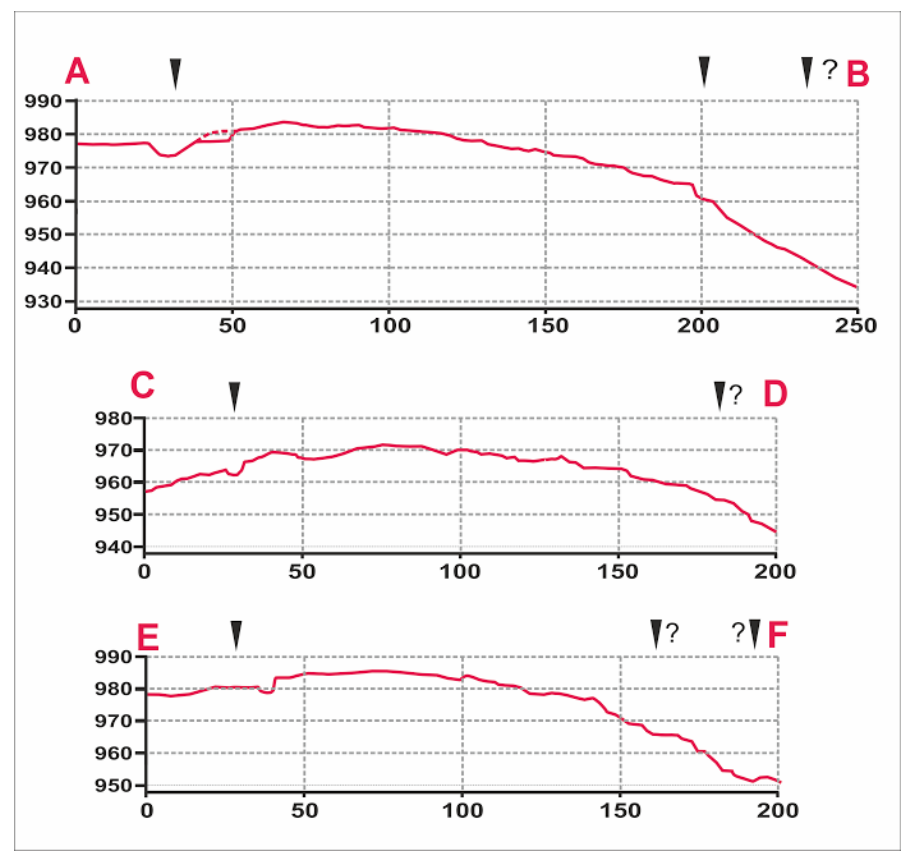

Fig. 5. Perfis topográficos do Alto da Cerca.

Fig. 5. Alto da Cerca topographical profiles. 


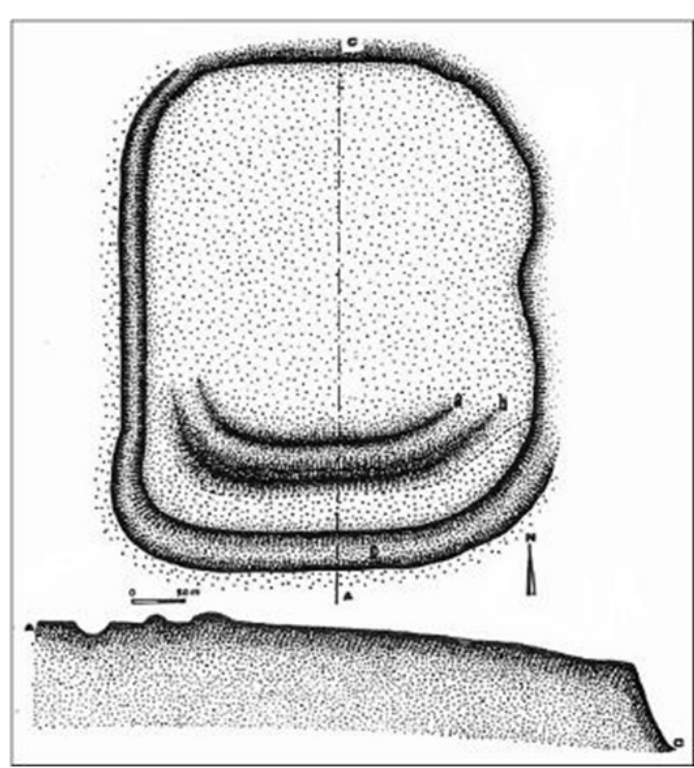

Fig. 6. Planta e perfil esquemáticos do Alto da Cerca (FREITAS 2001: 240).

Fig. 6. Alto da Cerca schematic plan and profile (FREITAS 2001: 240).

O traçado do fosso está mais bem definido no lado Ocidental, marcando uma linha de rutura na suave pendente local (Fig. 7). Deste modo, a vala, aberta na terra, teria uma largura de uns 5-6 m, sendo a altura da sua contra-escarpa de $2 \mathrm{~m}$ e a da escarpa de aproximadamente $5 \mathrm{~m}$. Assim, esta última reforça naturalmente a posição do parapeito defensivo, hoje amortizado. Depois de um breve espaço que se encontra colmatado por efeito de trabalhos agrícolas, o fosso volta a definir-se com precisão perto da esquina Norte, onde foi talhado na rocha natural. Também se pode apreciar com claridade a sua secção em U: enquanto a largura total oscila entre os 4,8 e os $5,30 \mathrm{~m}$, o talude exterior alcança os 1,5 m de altura e o interior aproxima-se dos $6 \mathrm{~m}$.

A esquina Norte apresenta uma curiosa particularidade. O fosso divide-se aqui em dois traçados: um externo que forma um ângulo retangular em tor- no da colina seguindo a pendente natural do terreno mas que, depois de uns 50 metros, começa a perderse e termina mesmo por confundir-se com o próprio terreno; um interior que, por seu lado, desenha um ângulo perfeito de $90^{\circ}$ escavado na rocha e perfila o lanço Norte do recinto a uma cota superior. A acusada pendente natural do terreno neste sector leva-nos a pensar na presença desnecessária de uma estrutura defensiva nesta zona. A densa cobertura vegetal arbustos, matagal, árvores- oculta quase por completo as estruturas, mas sem dúvida que o fosso continua embora se vá perdendo o seu rastro à medida que nos aproximamos da esquina Este. O talude interior nota-se com claridade e permite-nos apreciar que aqui se encontrava uma nova curvatura. Neste ponto pode também distinguir-se de novo uma pequena depressão a uma cota inferior que poderia corresponder-se com a continuação do fosso exterior.

Mas, tal como já referimos, o sector Este do recinto é praticamente irreconhecível na actualidade. O fenómeno não é recente, mas foi acentuado pela adaptação do terreno para a plantação de castanheiros. A morfologia da colina parece indicar que as esquinas Nordeste e Sudeste teriam uma curvatura aberta. Seguidamente, acompanhando a dinâmica geral das defesas do assentamento, desenvolviam-se dois lanços rectilíneos que confluiriam num ponto indeterminado.

Com base nestes dados pode-se aventurar que o eixo principal do recinto, com uma orientação NNE-SSW, tem uma extensão superior aos $210 \mathrm{~m}$ a contar da bordadura interior dos fossos exteriores. O perfil desenhado seguindo este alinhamento mostra ainda que, uma vez superada a pequena elevação do sector Meridional do sítio, a pendente descendente situa-se em valores a rondar os 11-12\%. Relativamente ao eixo menor, a sua longitude apenas pode estimar-se num máximo de $160 \mathrm{~m}$ tanto no sector Meridional como no Setentrional. Deste modo, a área neta do recinto, excluindo os fossos, não seria inferior a 2 ha.

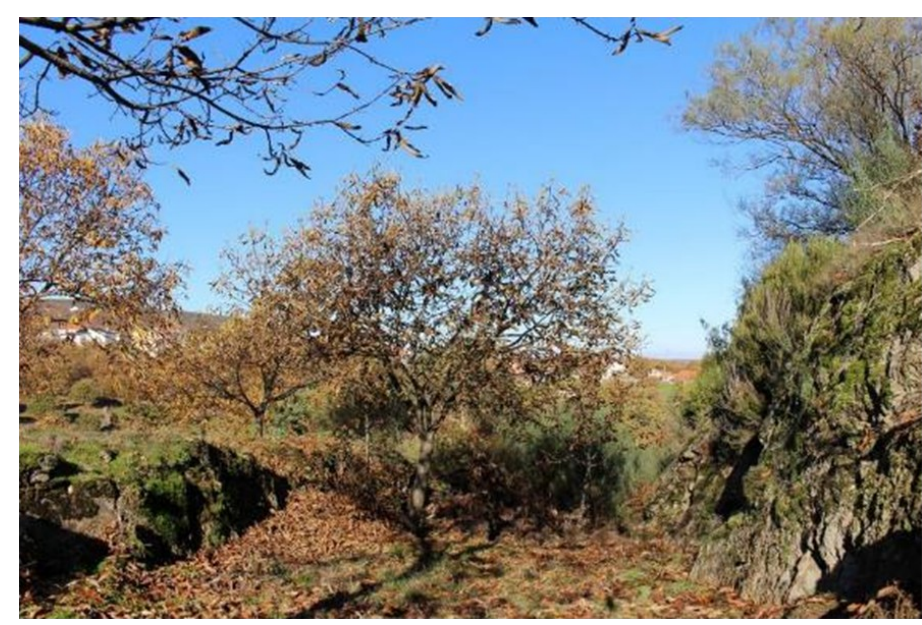

Fig. 7. Detalhe do fosso Ocidental escavado na rocha.

Fig. 7. Detail of the west ditch, carved in the rock. 


\subsection{Evidências materiais}

Devido à recente limpeza de várias parcelas para a plantação de castanheiros, tivemos oportunidade de observar a presença de alguns materiais cerâmicos em superfície durante o nosso reconhecimento do sítio. Os fragmentos, bastante escassos, têm as pastas e os acabados característicos da cerâmica comum de época romana. Não identificamos, todavia, qualquer evidência de material laterício, bastante frequente nos povoados de época romana, nem cerâmicas finas ou de tradição indígena. No entanto, a escassez da amostra impede-nos de aventurar qualquer hipótese interpretativa.

\subsection{Caracterização e interpretação}

Sem dúvida que o recinto do Alto da Cerca se afasta dos cânones de povoamento local da Idade do Ferro (FonTE 2015; Freitas 2001; LEMOS 1993; TEIXEIRA 1996). Os povoados fortificados da vertente Oriental da serra da Padrela caracterizam-se por assentarem em "castelos graníticos", com uma grande complexidade e monumentalidade ao nível do aparelho defensivo (LEMOS 1993 I: 221-225). Os castros desta zona apresentam normalmente várias linhas de muralha (duas ou mais) adossadas, em patamares sucessivos, denotando uma organização dos circuitos de muralhas e do estilo dos seus paramentos bastante característica. Na zona de mais fácil acesso os castros revelam a presença de pelo menos um fosso e de um campo de pedras fincadas. $\mathrm{Na}$ zona sobranceira ao fosso existe muitas vezes um torreão, sendo aqui que normalmente se juntam pelo menos duas linhas de muralha. Todavia, o apa- relho das muralhas é claramente o aspeto mais distintivo destes povoados (FONTE 2008). É normalmente constituído por dois paramentos paralelos, externo e interno, à base de silhares assentes em seco, preenchidos no seu interior com pedra miúda. A face externa denota uma preparação mais cuidada, em aparelho poligonal com pedra picada, sobretudo nas zonas mais visíveis e acessíveis dos povoados, formando um paramento com um claro efeito visual. A face interna é revestida com um aparelho de pedra menos cuidada e mais pequena.

Ao nível da sua localização e controlo territorial, estes povoados dividem-se em dois grandes grupos: os que controlam visualmente amplas extensões planálticas, e os que se encontram encravados em vales bastante estreitos e com um controlo visual bastante limitado.

Dentro deste último grupo, o Castelo dos Mouros de Jales ${ }^{8}$ (Alfarela de Jales, Vila Pouca de Aguiar), localizado a Sul do Alto da Cerca e em plena região mineira de Jales, contrasta claramente a todos os níveis com o assentamento que analisamos. Trata-se de um povoado fortificado que se implanta num meandro do rio Tinhela, estruturado em base a um duplo recinto de tendência circular (Fig. 8), com duas monumentais linhas de muralha de aparelho poligonal em granito e com o interior preenchido com pedra de xisto (Fig. 9), sendo a Sudoeste, a zona de mais fácil acesso, reforçado por um profundo fosso escavado no afloramento e outros dois fossos mais estreitos, divergentes do primeiro (FONTE 2015: 253-256).

No âmbito do segundo grupo, a Cerca de Ribas99 (Argeriz, Valpaços) (FREITAS 1989, 2001:

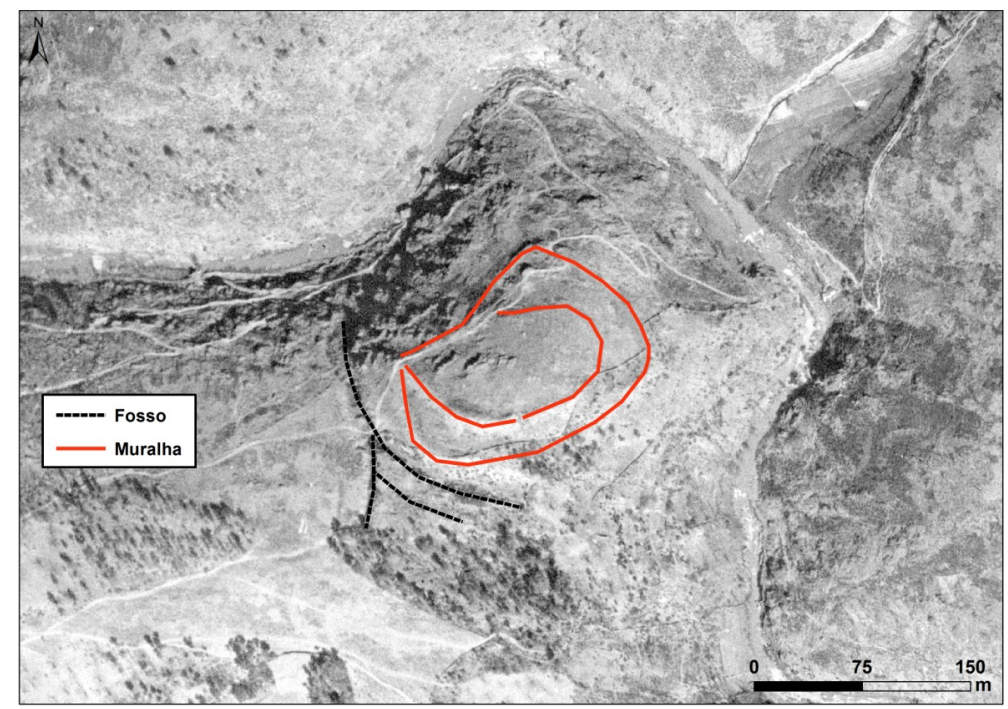

Fig. 8. Fotointerpretação do Castelo dos Mouros de Jales a partir da ortofoto do voo SPLAL de 1948.

Fig. 8. Photointerpretation of Castelo dos Mouros de Jales from the 1948 SPLAL flight orthophoto.

\footnotetext{
${ }^{8}$ Portal do Arqueólogo, CNS 15567.

${ }^{9}$ Portal do Arqueólogo, CNS 1836.
} 


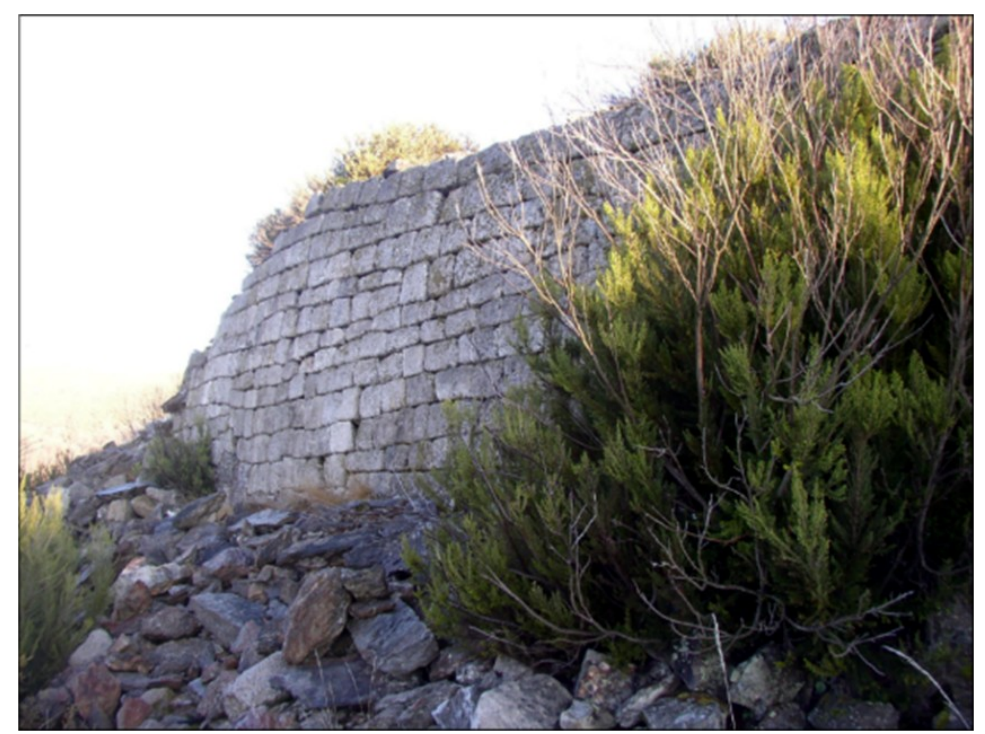

Fig. 9. Detalhe do aparelho poligonal da muralha do Castelo dos Mouros de Jales.

Fig. 9. Detail of the polygonal bond Castelo dos Mouros de Jales.

51-84; LEMOS II 1993: 523-525, sítio no 857; TEIXEIRA 1996: 109, sítio $\mathrm{n}^{\circ} 719$ ), localiza-se a Nordeste do Alto da Cerca, contrastando também com este sítio. Implanta-se num destacado cabeço granítico, com um excelente domínio visual sobre o planalto em redor. Estrutura-se em base a três linhas de muralha adossadas, formando três patamares consecutivos (Fig. 10). A Noroeste, na zona de acessibilidade mais fácil, foi aberto um profundo fosso escavado na rocha. Sobranceiro a este fosso existe um torreão subcircular, zona onde se juntam duas linhas de muralha, com um aparelho poligonal de pedra picada retangular assente a seco (Fig. 11). Uma quarta muralha exterior de aparelho ciclópico foi seguramente construída numa fase posterior.

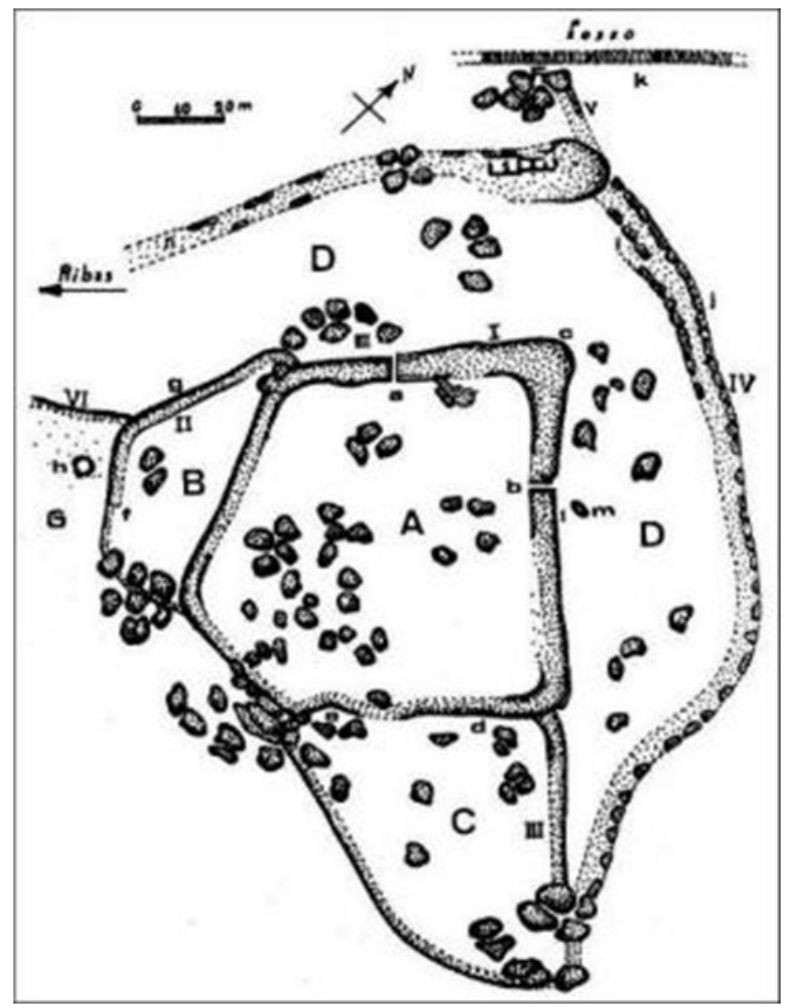

Fig. 10. Planta esquemática da Cerca de Ribas (Freitas 1989: 338, Fig. 4).

Fig. 10. Cerca de Ribas. Schematic plan (FreITAS 1989: 338, Fig. 4). 
A morfologia do Alto da Cerca é, de facto, perfeitamente compatível com um assentamento militar romano. Aliás, esta hipótese tinha já sido previamente avançada por Francisco Sande Lemos (1993 II: 548-549, sítio $\mathrm{n}^{\circ}$ 886; 2004: 417), considerando que, face à particularidade do seu sistema defensivo, poderá tratar-se de um "campo militar romano, tanto mais que se encontra localizado na zona que dá acesso ao distrito mineiro de Três Minas e Jales" (LEMOS 1993 II: 549).

Com efeito, a disposição do recinto em planta poligonal, com lanços rectos e esquinas arredondadas, a sua imposição sobre o terreno, colina em pendente, e o carácter delimitador, mais que defensivo, que manifesta o fosso em alguns sectores, entroncam com os princípios da técnica de castrametação romana. Porém, o Alto da Cerca não tem de momento um paralelo direto a nível peninsular. Na morfologia do fosso encontramos elementos que afastam este recinto dos princípios que regem os castra aestiua (DAVIES \& JONES 2006; Peralta-Labrador 2002c; Welfare \& SWAN 1995): trata-se de uma obra massiva, laboriosa -secções perfeitamente cortadas na rocha- e claramente excessiva para um simples acampamento. Não encaixa tampouco com o observado nas bases militares permanentes escavadas na Hispania, onde o habitual é existir um fosso em V -fossa fastigata- e um uallum feito de terra ou uma muralha de pedra no interior ${ }^{10}$.

Em muitos sentidos, o assentamento de San Isidro (Astúrias, Espanha) poderia ser um bom paralelo (VILLA-VALDÉS 2007a: 45-48, 2007b: 208 -210) (Fig. 12). Ainda que este recinto tenha sido inicialmente catalogado como castro (CARROCERAFERNÁNDEZ, 1990, 1992), a sua localização e morfologia afastam-se também dos padrões locais de povoamento da Idade do Ferro. Apresenta uma planta poligonal com esquinas arredondadas $(0,57$ ha), bem delimitada pela presença de um fosso massivo. A fundação deste assentamento ocorreu na segunda metade do século I d. C. de acordo com os materiais encontrados e a sua missão teria sido a de albergar um pequeno contingente militar encarregue do controlo de uma região onde a mineração aurífera adquirirá uma grande importância. Contudo, San Isidro oferece uma maior variedade e complexidade na disposição dos seus elementos defensivos quando comparado com o Alto da Cerca.

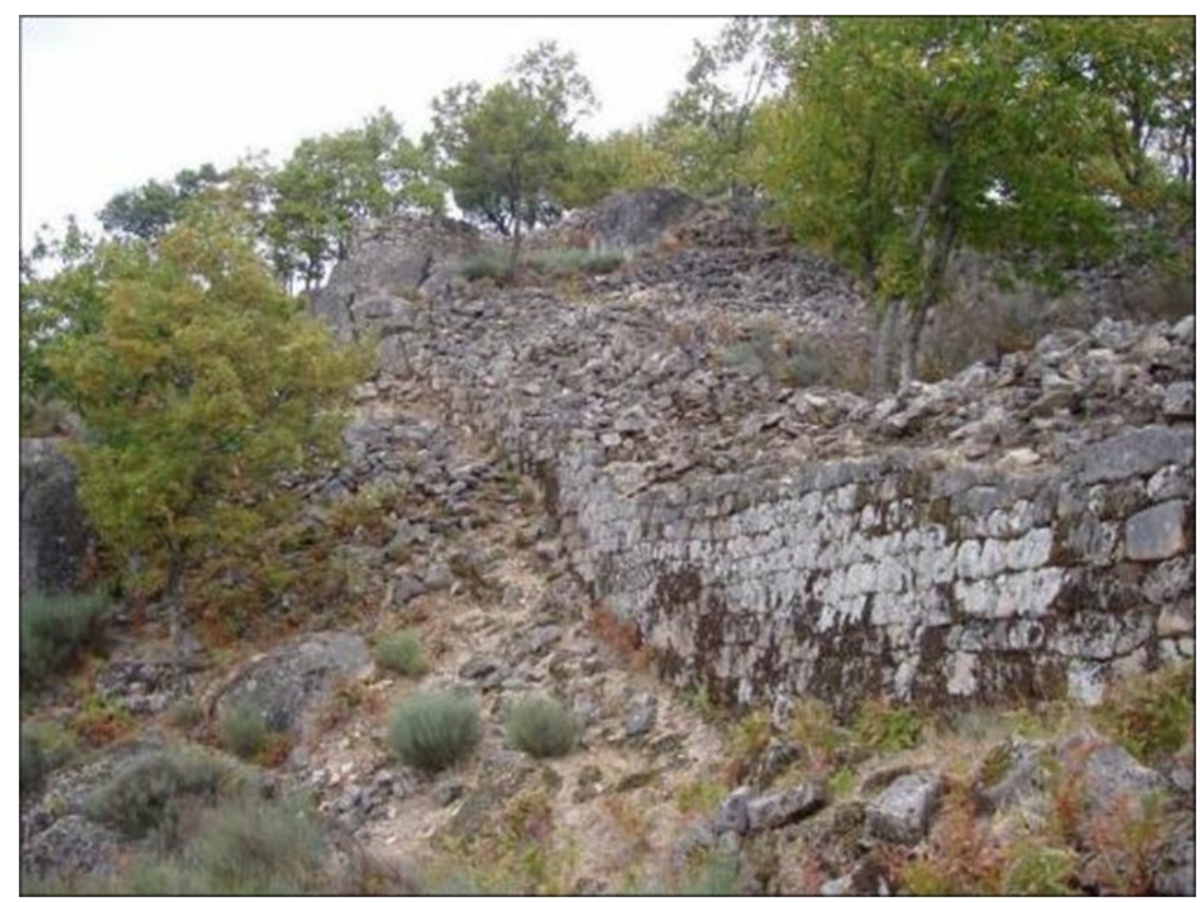

Fig. 11. Pormenor do aparelho poligonal da muralha da Cerca de Ribas, notando-se em cima o torreão. Fig. 11. Detail of the polygonal bond at Cerca de Ribas, with the turret above. 


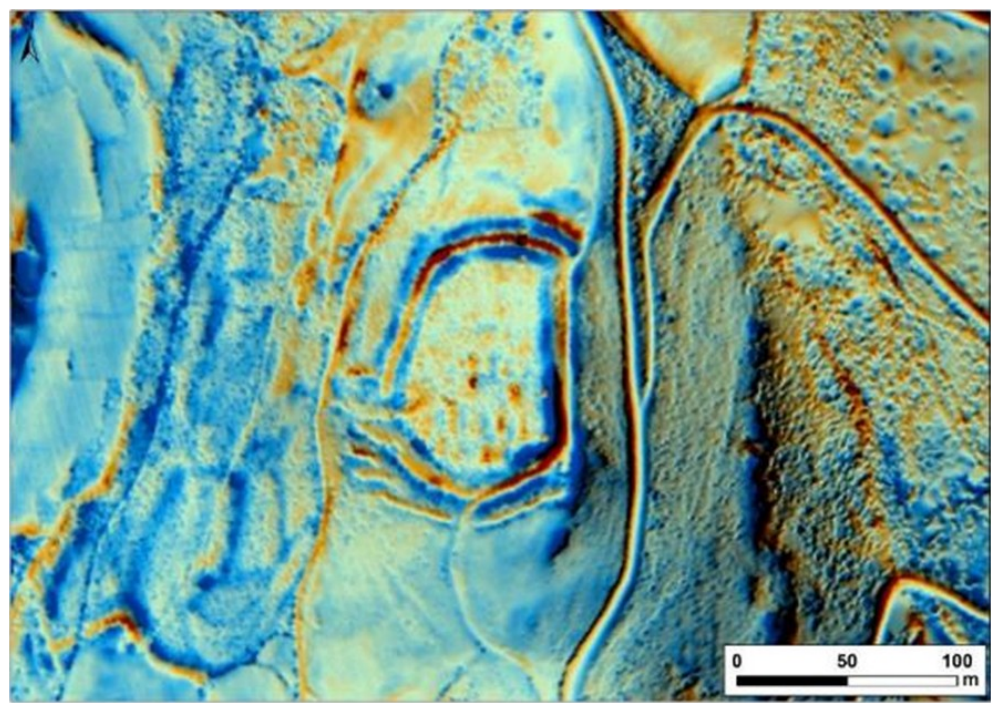

Fig. 12. Assentamento de San Isidro (MDT interpolado a partir dos dados LiDAR do PNOA-IGN com aplicação do Resampling Filter disponível no software SAGA ${ }^{11}$ ). Fig. 12. San Isidro settlement (DTM interpolated from the PNOA-IGN LiDAR data with application of SAGA GIS- Resampling Filter).

\section{CONTEXTUALIZAÇÃO HISTÓRICO- ARQUEOLÓGICA}

\subsection{O modelo locacional}

Os cálculos de visibilidade ${ }^{12}$ realizados permitem-nos comprovar, até certo ponto, o grau de controlo visual que desde o recinto do Alto da Cerca se pode ter tido sobre o território circundante. Ainda que em termos gerais a colina apresente uma altitude relativa elevada em relação à sua envolvente, a proximidade de outras elevações de envergadura similar limita significativamente o seu campo de visão. Em termos quantitativos, embora se dominem as proximidades do recinto, a visibilidade total desde o mesmo não alcança $6 \%$ da sua envolvente ${ }^{13}$. Ao expressar estes dados de forma qualitativa, isto significa que o Alto da Cerca controla visualmente a zona planáltica da vertente Oriental da Serra da Padrela, bem como o vale superior do rio de Curros, que corre para Sul em direção à zona mineira de Tresminas, controlando, assim, o acesso a esta última zona pelo Norte. O esporão onde se implanta o Alto da Cerca está virado a Nordeste, para onde se concentra também a sua visibilidade.

Por outro lado, os cálculos de prominência visual ${ }^{14}$ permitem-nos aproximar ao impacto topográfico que o recinto pode ter tido sobre o território envolvente, computando-se todos os lugares desde os quais o sítio seria perfeitamente distinguível. De novo, o recinto parece destacar sobre a sua envolvente imediata, mas à medida que nos afastamos os valores decrescem abruptamente, pelo que claramente a proeminência visual não seria uma variável locacional determinante, particularmente a larga distância ${ }^{15}$.

O Alto da Cerca não parece estar relacionado com o povoamento da Idade do Ferro da zona, uma vez que apenas tem intervisibilidade com um castro, o Cabeço de Argemil $^{16}$ (Serapicos, Valpaços) (FREITAS, 2001 320-323; LEMOS 1993 II: 535, sítio 868; TEIXEIRA 1996: 108, sítio 716), que se localiza a cerca de $8 \mathrm{~km}$ para Nordeste. Porém, na sua envolvente imediata, a cerca de $800 \mathrm{~m}$ para Norte, encontra-se referenciada no topónimo "Milagres"17 uma dispersão em superfície de materiais de época romana, nomeadamente tegulae, cerâmica comum romana e fragmentos de sigillata, bem como vestígios de opus signinum e pequenos silhares de granito e duas bases de coluna, que se deverão relacionar com a existência no local de um povoado aberto de época romana.

Desta forma, o Alto da Cerca parece controlar visualmente o acesso a Tresminas desde o Norte através da vertente Leste da serra da Padrela, pelo que procuraremos agora contextualizar este sítio em relação à exploração mineira de Tresminas (Fig. 13).

\footnotetext{
${ }^{11}$ System for Automated Geoscientific Analyses - SAGA (version 2.2.3, 64 bit) (CONRAD et al. 2015).

${ }^{12}$ Utilizamos o software ArcMap 10.3 (ESRI Inc.), em particular o seu algoritmo viewshed, com um OFFSETA (altura do visor) de $2,8 \mathrm{~m}(1,2 \mathrm{~m}$ talude $+1,6 \mathrm{~m}$ altura média da visão do ser humano).

${ }^{13} \mathrm{~A}$ partir dos limites do recinto dividimos o espaço em cinco intervalos - buffers- arbitrários de visão: a 370, 740, 1481, 4443 e a $8886 \mathrm{~m}(1 / 4,1 / 2,1,3$ e 6 milhas romanas respetivamente). Estes cálculos demonstram que nos intervalos de ação imediata, a visibilidade é bastante boa (78\% e $58 \%$ ), mas a partir do espectro médio $(29,5 \%)$ a descida é bastante elevada $(8,4 \%$ e $3,4 \%)$.

${ }_{14}^{14}$ Para tal utilizamos de novo o algoritmo viewshed do software ArcMap, incluindo novas variáveis de análise (OFFSETB de $1,7 \mathrm{~m}$ altura média do ser humano).

${ }_{15}^{15}$ Para tal utilizamos de novo o algoritmo viewshed do software ArcMap, incluindo novas variaveis de analise (OFFSETB de 1,7 m os buffers antes propostos (vid. n. 12), os valores seriam de $89,5 \%, 69,7 \%, 38,3 \%, 11 \%$ e $4,4 \%$ respetivamente.

${ }_{17}^{16}$ Portal do Arqueólogo, CNS 13236

${ }^{17}$ Portal do Arqueólogo, CNS 13240
} 


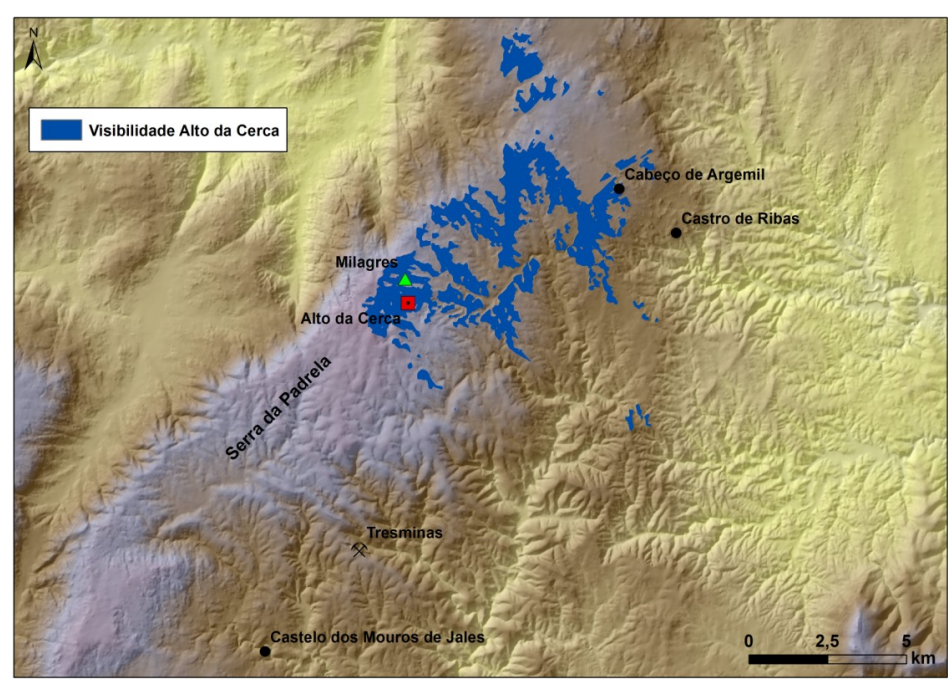

Fig. 13. Visibilidade do Alto da Cerca e principais sítios arqueológicos referidos no texto. Fig. 13. Viewshed from Alto da Cerca and main archaeological sites mentioned in the text.

\subsection{Zona mineira de Tresminas}

A zona mineira de $\operatorname{Tresminas}^{18}$, juntamente com a de Jales ${ }^{19}$ e da Gralheira ${ }^{20}$, formava um dos maiores complexos industriais mineiros na Antiguidade, cuja exploração parece ter-se iniciado ainda em época de Augusto (WAHL 1988).

A mineração foi realizada pelo sistema de cortas a céu aberto, embora pareça ter havido um primeiro momento de exploração subterrânea, baseada na abertura de poços e galerias de prospeção, seguido do desmonte de filões na horizontal e em profundidade, pelo que só depois se terá passado à exploração a céu aberto (BATATA 2013: 788), hipótese já anteriormente avançada por Claude
Domergue (2008: 140-141). Este complexo sistema de galerias destinava-se também ao transporte de materiais e ao escoamento das águas para drenagem das cortas. Em Tresminas existem três cortas de exploração a céu aberto: cortas de Covas, da Ribeirinha e dos Lagoinhos, sendo de destacar as duas primeiras pelas suas extraordinárias dimensões e profundidade (Fig. 14). Existem também uma série de barragens, depósitos de água e de canais de abastecimento associados às frentes de exploração mineira, uma vez que a exploração industrial dos depósitos auríferos exigia um abastecimento de água metódico e sistemático.

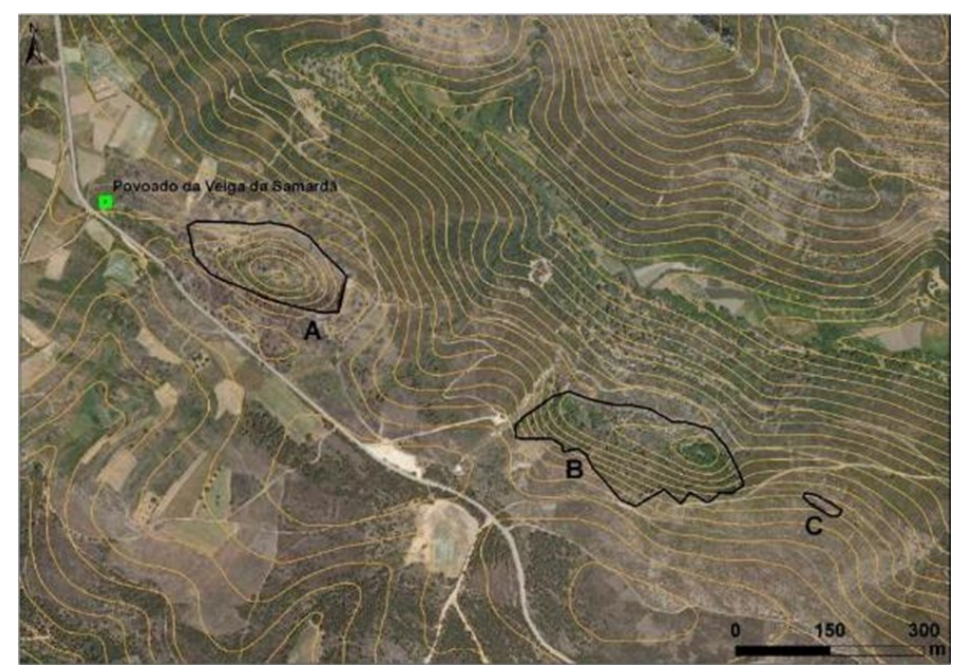

Fig. 14. Localização do povoado romano da Veiga da Samardã em relação às cortas de Covas (A), Ribeirinha (B) e Lagoinhos (C) sobre ortofoto actual (Ortos_DGRF_2004_06). Fig. 14. Location of the Roman settlement of Veiga da Samardã in relation with the pits of Covas (A), Ribeirinha (B) and Lagoinhos (C) on recent orthophoto (Ortos_DGRF_2004_06).

\footnotetext{
${ }^{18}$ Portal do Arqueólogo, CNS 3623.

${ }^{19}$ Portal do Arqueólogo, CNS 1137.

${ }^{20}$ Portal do Arqueólogo, CNS 17775.
} 
Existe pelo menos um povoado mineiro arqueologicamente constatado como tal, o povoado da Veiga da Samardã ${ }^{21}$, na periferia imediata das frentes mineiras de Tresminas, nomeadamente da corta de Covas, com uma cronologia genérica de ocupação entre os séculos I e II d.C. (BATATA 2009, 2011, 2013; LEMOS \& MARTINS 2014: 342344; WAHL 1988).

O Alto da Cerca encontra-se já fora da zona mineira de Tresminas, embora na sua periferia imediata a Norte. Entre o Alto da Cerca e Tresmi- nas tinha já sido referida a existência de um possível canal (Canal 1) no topónimo "Fragas Cortadas"22 (Curros, Valpaços) (FrEITAS 2001: 201205) (Fig. 15 e 16). Este canal foi também identificado por Jürgen Wahl (2003: 498-501). Dirige-se para Sul para Tresminas, passando sensivelmente pela cota dos 700 metros, aparentemente em direção à corta da Ribeirinha, embora o canal esteja a uma cota inferior, pelo que não será de supor uma relação direta entre ambos elementos.

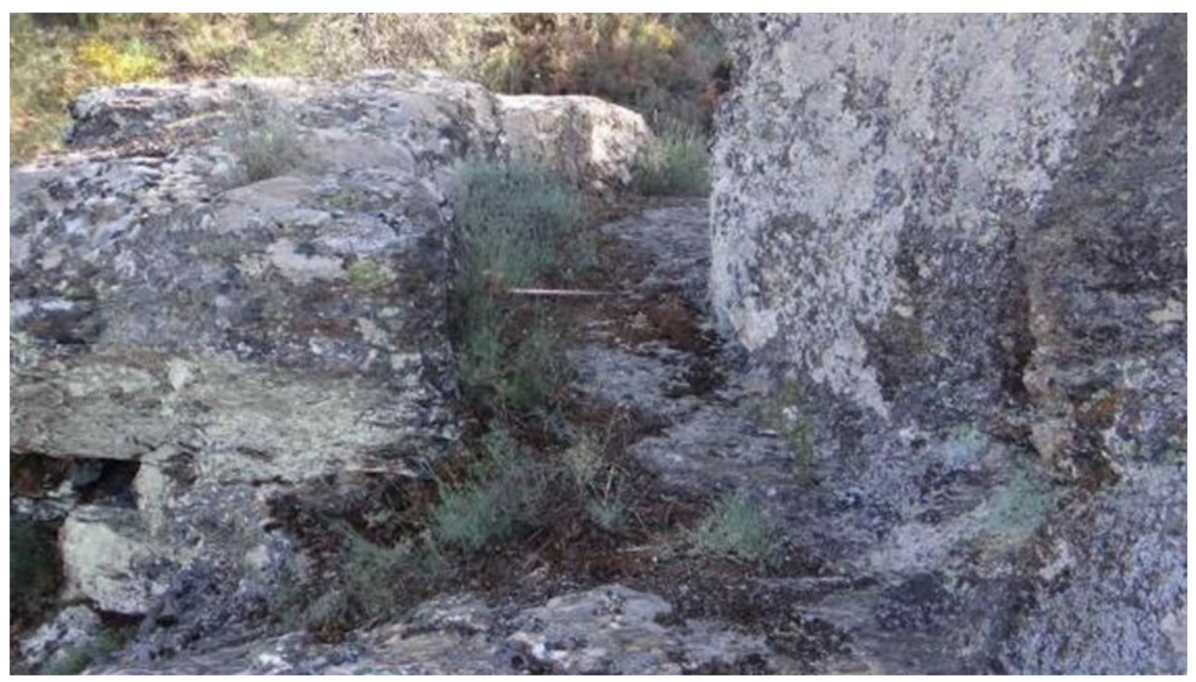

Fig. 15. Troço de canal escavado na rocha na zona das "Fragas Cortadas".

Fig. 15. Section of the channel carved into the rock in the area of "Fragas Cortadas".

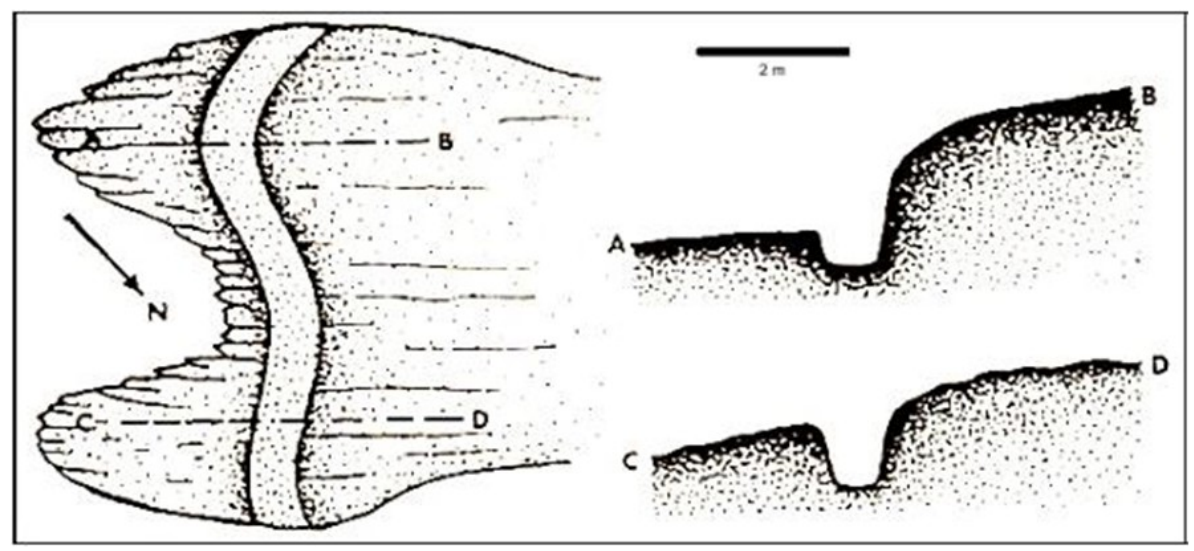

Fig. 16. Planta e perfis esquemáticos das "Fragas Cortadas" (Freitas 2001: 204).

Fig. 16. "Fragas Cortadas" schematic plan and profile (Freitas 2001: 204)

Por informação do senhor Maurício da Eira Laje, habitante da aldeia de Curros e que tinha sido o informante de Adérito Medeiros Freitas (2001: 197-206) para a freguesia de Curros, reconhecemos um segundo canal (Canal 2) a uma cota superior, em torno dos 800 metros. Este canal também se dirige para Sul em direção a Tresminas, ligando com um outro troço de canal já conhecido na zona das "Fragas Negras" (Tresminas, Vila Pouca de Aguiar) (Fig. 17), que estaria supostamente relacionado com o abastecimento de água a uma instalação de lavagem de minério na zona das "Fragas

\footnotetext{
${ }^{21}$ Portal do Arqueólogo, CNS 30567.

${ }^{22}$ Portal do Arqueólogo, CNS 19420
} 
das Covas" (WAHL 1998: 66-68; WAHL-CLERICI 2013: 41-43), que era composto por "(...) dois sistemas paralelos que aproveitavam a inclinação constante da encosta e eram dotados, cada um, de pelo menos 17 postos operacionais unidos em série, postos esses que se estendiam por uma distância de cerca de $200 \mathrm{~m}$ da crista até ao vale." (WAHL 1998: 66) (Fig. 18). Mais recentemente, estes depósitos escalonados foram interpretados como fazendo parte de um sistema de tratamento para a moagem de minério e evacuação de estéreis através do uso de força hidráulica (SÁNCHEZ-PALENCIA 2015: 192-193).

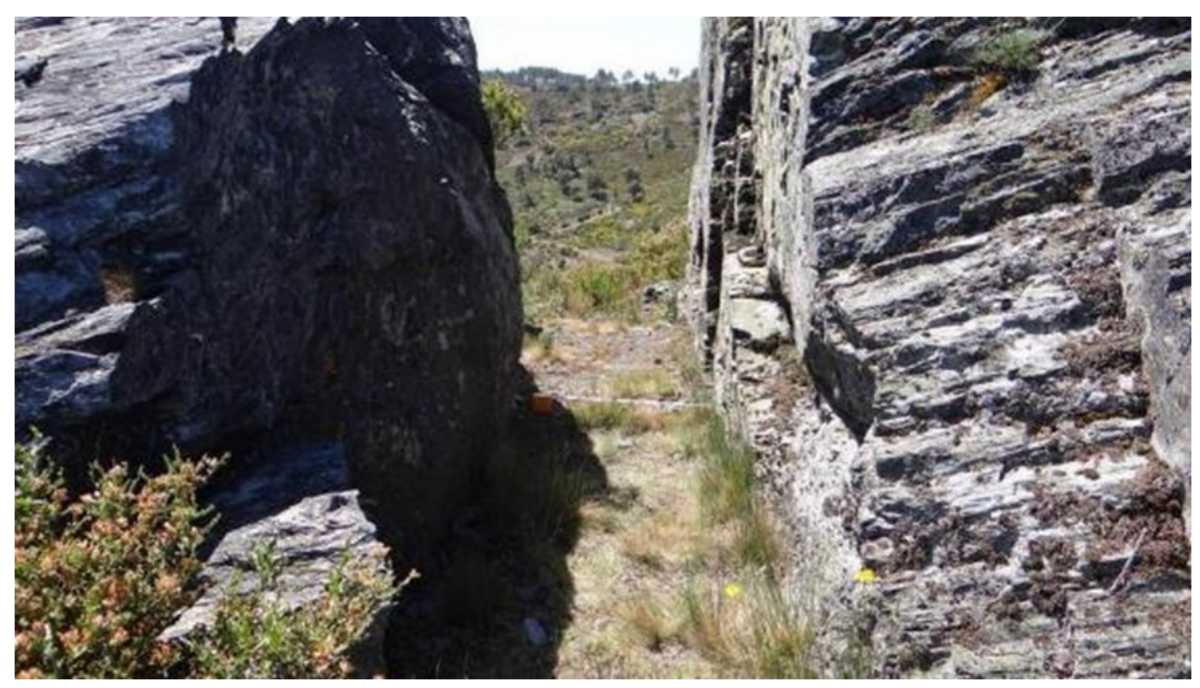

Fig. 17. Troço de canal escavado na rocha na zona das "Fragas Negras", com a Corta de Covas ao fundo. Fig. 17. Section of the channel carved into the rock in the area of "Fragas Negras". Covas pit in the background.

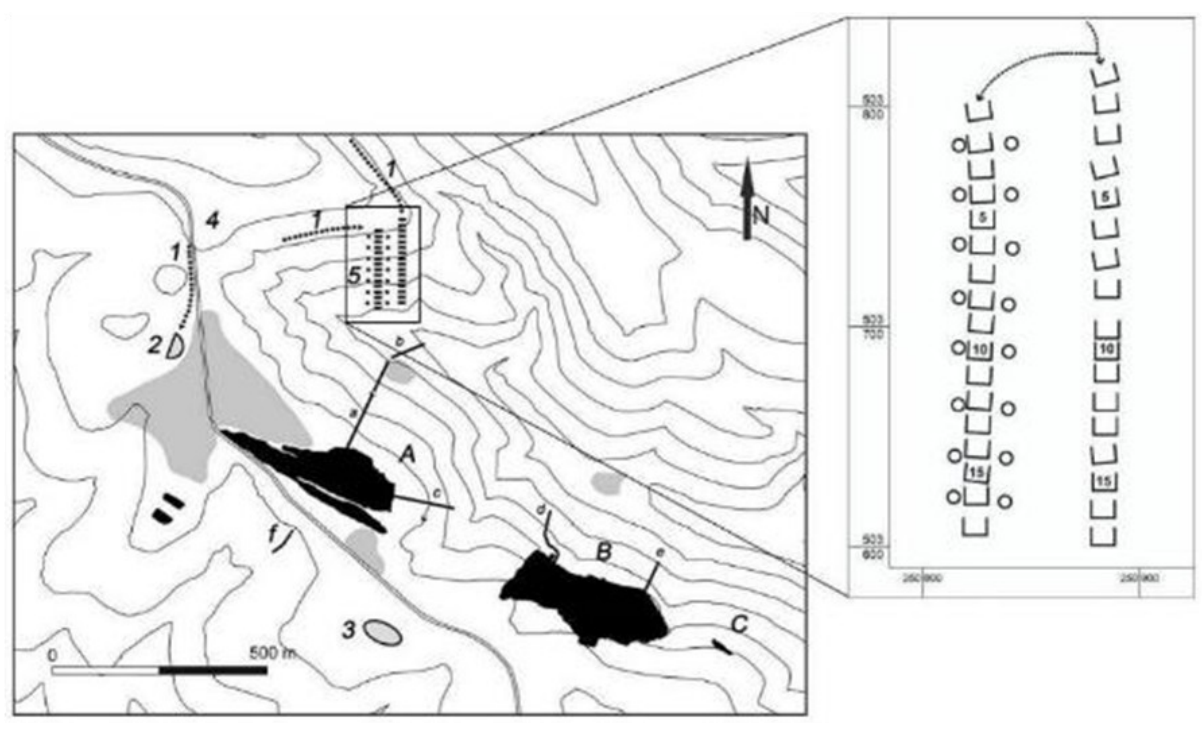

Fig. 18. Mapa da zona mineira de Tresminas, com destaque para a instalação de lavagem de minério (adaptado de HELFERT et al. 2013: 208, Fig. 1 e WAHL-Clerici 2013: 41, Fig. 3).

Legenda: 1 - Aquedutos, 2 - Reservatório de água, 3 - Anfiteatro?, 4 - Necrópole, 5 - Instalação de lavagem de minério, A - Corta de Covas, B - Corta da Ribeirinha, C - Corta dos Lagoinhos, a - Galeria do Pilar, b-Galeria do Texugo, c - Galeria dos Alargamentos, d - Galeria dos Morcegos, e - Galeria do Buraco seco, $\mathrm{f}-$ Galeria Esteves Pinto.

Fig. 18. Map of Tresminas mining area, especially the ore washing plant (adapted from Helfert et al. 2013: 208, Fig. 1 and Wahl-Clerici 2013: 41, Fig. 3).

Legend: 1 - Aqueducts, 2 - Water tank, 3 - Amphitheater?, 4 - Necropolis, 5 - Ore washing plant, A - Covas pit, B - Ribeirinha pit, C - Lagoinhos pit, a - Pilar gallery, b - Texugo gallery, c - Alargamentos gallery, d Morcegos gallery, e - Buraco seco gallery, $\mathrm{f}$ - Esteves Pinto gallery. 
Em algumas zonas estes canais foram escavados na própria rocha o que garantia uma maior estabilidade, mas nas zonas onde era necessário salvar a pendente do terreno os canais eram construídos sobre muros de contenção em pedra seca. A água seria transportada por ação da gravidade, pelo que os canais teriam que ser construídos com um ligeiro desnível decrescente, aproximadamente de $0,5 \%$, entre o caput aquae e o ponto terminal, perfeitamente adaptados à geomorfologia do terreno (DOMERGUe 2012; LÓPEZ-BoAdo 2005; MATÍASRODRÍGUEZ 2006a, 2006b, 2008; RIERA 2005; SÁNCHEZ-PALENCIA \& PÉREZ-GARCÍA 2000).

Encontrava-se já localizada uma barragem a Sul de Tazém na ribeira de Frades (WAHL-CLERICI et al. 2012: 21, Fig. 1, $\mathrm{n}^{\circ}$ 9), sendo precisamente aqui a zona de abastecimento do canal 2. Face à existência do canal 1 a uma cota inferior, teria muito provavelmente que existir uma outra barragem ainda não localizada. Uma possibilidade seria a Sul de Valizelos na ribeira do Salgueiral, perto do topónimo Vale Grande, embora não seja de excluir uma localização mais a Norte.

Todavia, será necessário proceder-se a uma cartografia rigorosa do traçado de ambos canais, sobretudo da sua parte final, de forma a se clarificar qual poderá ter sido a finalidade de ambos no apoio à exploração mineira de Tresminas. Apresentamos, porém, uma proposta de traçado para ambos canais, com base nos troços que verificamos em campo, os quais interligamos seguindo sensivelmente a mesma linha de cota (Fig. 19).

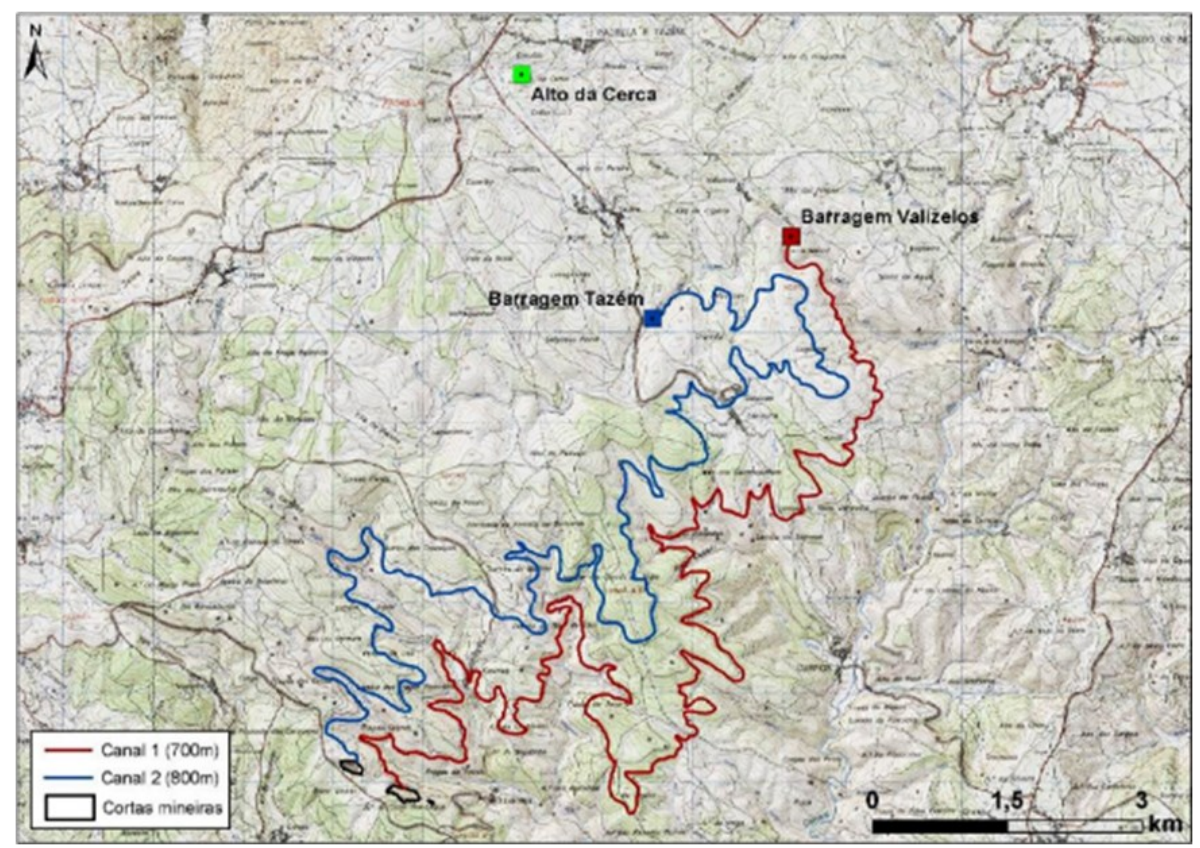

Fig. 19. Localização do Alto da Cerca na Carta Militar de Portugal à escala 1:25.000 do IGeoE, série M888, folhas $\mathrm{n}^{\mathrm{o}} 60,61,74$ e 75, $2^{\mathrm{a}}$ edição, em relação à rede hidráulica (canais e barragens) que se dirige para Sul em direcção a Tresminas.

Fig. 19. Location of the Alto da Cerca in the Military Map of Portugal, from the Army Geographical Institute, (scale 1/25.000, M888 series, $\mathrm{n}^{\circ} 60,61,74$ and 75,2 nd edition), in relation with the hydraulic network (channel and dams) that runs south towards Tresminas.

Posto isto, será que a presença militar romana no Alto da Cerca, obviamente se esta se vier efectivamente a confirmar, se poderia eventualmente relacionar com o início da exploração mineira e com a criação das necessárias infra-estruturas, em particular a rede hidráulica que abastecia a zona mineira de Tresminas? Esta tratou-se de uma impressionante obra de engenharia hidráulica com quilómetros de extensão, obedecendo a rigorosos critérios de planificação topográfica, a par da construção de barragens e de reservatórios de água, cuja construção poderia ter beneficiado dos conheci- mentos técnicos do próprio exército romano, que estaria desde o início diretamente envolvido na conceção e edificação das infraestruturas necessárias à exploração mineira.

Jürgen Wahl (2003: 498) refere a existência de cinco ou seis canais que compunham a rede hidráulica de abastecimento a Tresminas, embora não avance com os seus traçados exatos. Menciona -se também a existência das barragens da Ferraria $^{23}$ e de Vale das Veias ${ }^{24}$, ambas no rio Tinhela, em relação direta com o canal e túnel do Pedro$\mathrm{so}^{25}$, que tem uma parte a céu aberto e outra subter-

\footnotetext{
${ }^{23}$ Portal do Arqueólogo, CNS 17884

${ }^{24}$ Portal do Arqueólogo, CNS 17885.
}

${ }^{25}$ Portal do Arqueólogo, CNS 17905. 
rânea, e que aparentemente se dirigia para um reservatório de água de consideráveis dimensões no sítio de Entre Vinhas ${ }^{26}$ localizado a Oeste da corta de Covas, constituindo a parte mais bem conhecida do sistema de armazenamento e distribuição de água que abastecia o complexo mineiro de Tresminas (FORTES 2009; MARTINS 2012; WAHL 1988).

Por outro lado, queremos destacar as centenas de moinhos de pilões identificados por toda a zona mineira de Tresminas e que eram utilizados na trituração do minério (WAHL 1998: 66-67), não sendo de colocar de lado a possibilidade de estes terem sido alimentados precisamente com energia hidráulica (HIRT 2010: 35-36; WILSON 2002: 22 24). De facto, alguns canais parecem relacionar-se com zonas de elevada concentração deste tipo de pilões, nomeadamente o que definimos como Canal 1, que aparentemente termina em baixo da corta da Ribeirinha, justamente onde se regista uma grande densidade destes pilões.

Por esta zona passaria uma via secundária que faria a ligação entre o vale do Douro e o iter XVII (It. Ant. Wess. 422.2-423.5), cujo traçado foi já genericamente definido (LEMOS 2004). O tramo entre Justes e Jales encontra-se devidamente cartografado (LOPES et al. 1994), ao contrário do traçado entre Jales e o iter XVII, que é ainda relativamente mal conhecido, devido à ausência de indicadores arqueológicos viários seguros. Segundo estes últimos autores, esta via faria a ligação entre Emerita Augusta (Mérida) e Aquae Flaviae (Chaves), cruzando as zonas mineiras de Jales, Gralheira e Tresminas, e ligando mais a Norte ao iter XVII e daí a Aquae Flauiae (Fig. 20). A principal evidência material da existência desta via é a Ponte do Arco ou de Barrela ${ }^{27}$ (Vreia de Jales, Vila Pouca de Aguiar) (Fig. 21), bem como a estátuaestela do $\mathrm{Marco}^{28}$, um elemento pré-existente que se encontra mesmo ao lado do traçado da via, podendo ter sido integrado na construção desta nova paisagem romana (ibid.) (Fig. 20).

$\mathrm{Na}$ zona mineira de Tresminas a presença militar romana está atestada epigraficamente, em concreto destacamentos da legio VII Gemina e da cohors I Gallica equitata ciuium Romanorum ( $A E$ 1907, $150=$ CIL II 2389 = HispEpigr. 2, 1990, 891; AE 1907, 151 = HispEpigr. 7, 1997, 1259; LE RouX 1982; Redentor 2010). Apesar de se tratar de inscrições de meados do século II d.C., desconhecem-se, pelo menos até ao momento, os sítios concretos onde estes destacamentos estariam instalados.

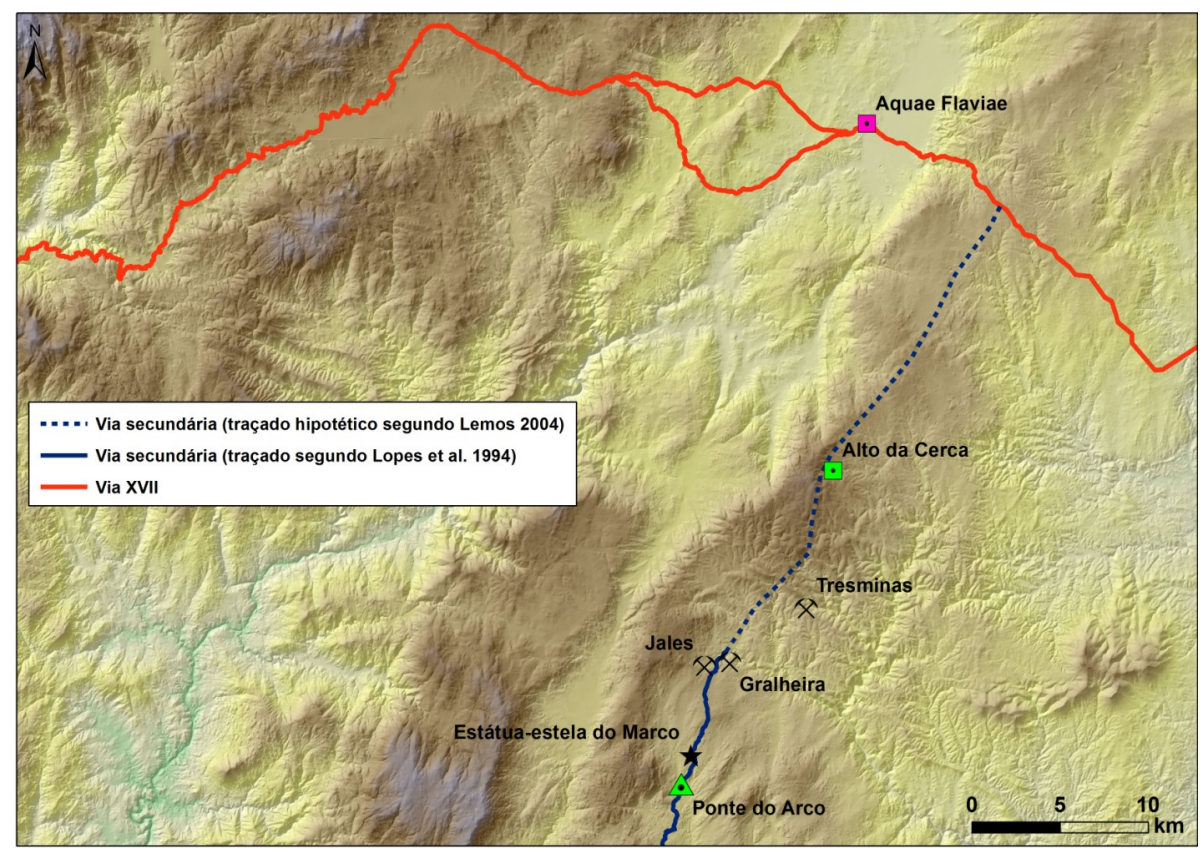

Fig. 20. Via romana secundária que ligava o vale do Douro ao iter XVII, cruzando as zonas mineiras de Jales, Gralheira e Tresminas e passando perto do Alto da Cerca.

Fig. 20. Secondary Roman road connecting the Douro valley with the iter XVII, throughout the mining areas of Jales, Gralheira and Tresminas, and passing near Alto da Cerca.

\footnotetext{
${ }^{26}$ Portal do Arqueólogo, CNS 31012.

${ }^{27}$ Portal do Arqueólogo, CNS 18008. Trata-se de uma pequena ponte em granito de um só arco, sobre o rio Pinhão, de construção romana, restando ainda os pilares e o arco de volta perfeita que apresentam várias pedras almofadadas e marcas de forfex, tendo posteriormente sofrido diversas remodelações ${ }^{28}$ Portal do Arqueólogo, CNS 18007.
} 


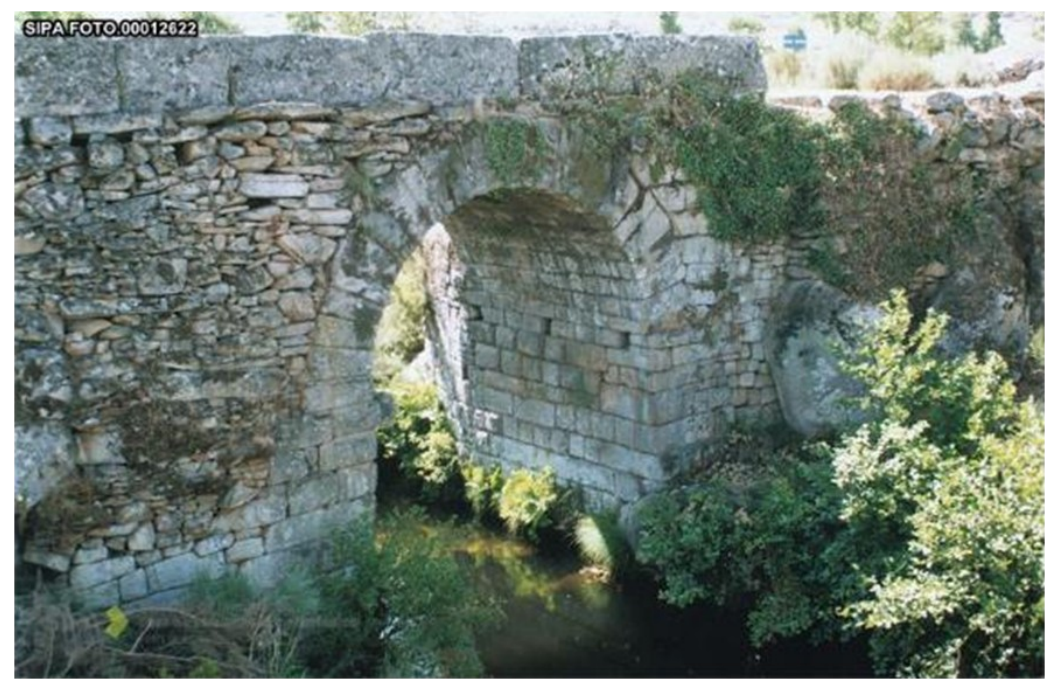

Fig. 21. Ponte do Arco ou de Barrela (ㄷ) Sistema de Informação para o Património Arquitectónico - SIPA, Instituto da Habitação e da Reabilitação Urbana, I.P. - IHRU).

Fig. 21. Bridge of Arco or Barrela (C Sistema de Informação para o Património Arquitectónico SIPA, Instituto da Habitação e da Reabilitação Urbana, I.P. - IHRU).

O recinto do Alto do Cimo dos Lagos ${ }^{29}$, situado imediatamente a Sul da corta de Covas e a Sudoeste da corta da Ribeirinha (Fig. 22), chegou a ser proposto como um possível acampamento militar romano atípico (ALMEIDA 1973: 558). Outros autores apontam antes para a existência de um pequeno anfiteatro (MARTINS et al. 2011: 112), tal como aliás já tinha sido inicialmente proposto por Jürgen Wahl (1988: 237-238), havendo também quem sustente a possibilidade de se tratar de um hipódromo (BATATA 2009: 419). Mais recentemente, foi de novo avançada a hipótese de este recinto se tratar de um assentamento não permanente de carácter militar, face à sua morfologia em U aberto em direção a Este e com uma superfície não nivelada (SÁNCHEZ-PALENCIA \& CURRÁSREFOJOS 2015: 282; SÁNCHEZ-PALENCIA 2015: 201-202). Com efeito, a análise da fotografia aérea histórica permite reconhecer um recinto de forma elíptica que vai perdendo definição para Este, mas de momento não contamos com indícios arqueológicos suficientemente sólidos como para considerar a sua filiação militar.

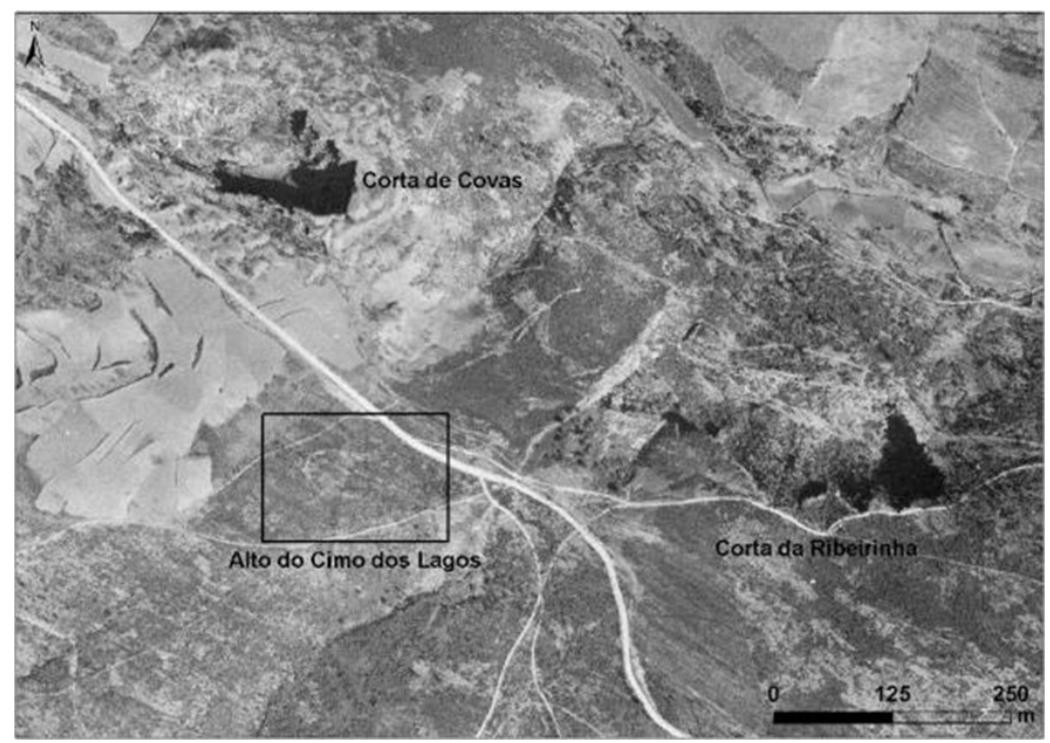

Fig. 22. Alto do Cimo dos Lagos na ortofoto do voo SPLAL de 1948.

Fig. 22. Alto do Cimo dos Lagos (1948 SPLAL flight orthophoto).

\footnotetext{
${ }^{29}$ Portal do Arqueólogo, CNS 17904.
} 


\section{CONCLUSÕES}

Em primeiro lugar, o recinto do Alto da Cerca afasta-se claramente do padrão morfológico e locacional dos castros da zona. As evidências arqueológicas disponíveis reforçam a ideia de que estamos perante um assentamento fortificado ocupado durante o período romano alto-imperial. Num contexto em que a violência era exercida de forma monopolista pelo exército, resulta difícil acreditar que estamos diante de um povoado civil. A hipótese de uma ocupação militar pode resultar num princípio difícil de aceitar devido ao facto do recinto se afastar dos cânones de castrametação mais comumente reconhecíveis mas, como se tem vindo a confirmar noutros pontos do Noroeste Peninsular, as formas nas quais a presença militar romana se manifesta tendem a diversificar-se no registo arqueológico (COSTA-GARCíA 2013). É por isso que, longe de nos prendermos a princípios rígidos de classificação, devemos antes ampliar o espectro da nossa análise através da introdução de novas variáveis.

Neste caso concreto também é muito importante o peso de outros fatores conjunturais. A existência de um sítio "anómalo" dentro dos padrões de povoamento local nas proximidades de uma importante zona mineira parece-nos deveras significativa. Pensemos, salvando as diferenças, no significativo caso dos castros de Chao San Martín e de San Chuis, ambos nas Astúrias, cuja reocupação e recondicionamento se relacionaram com a presença do exército e da administração romana (MARÍN-SUÁREZ et al. 2008; MONTE-LÓPEZ \& VILLA-VALDÉS 2015; VILLA-VALDÉS 2007b). A presença do exército romano no Alto da Cerca poderia relacionar-se com a própria proteção e controlo do distrito mineiro de Tresminas, mas também com questões logísticas e técnicoadministrativas de planificação, administração e organização territorial, sendo que o exército não participaria diretamente nos trabalhos de exploração mineira, que seriam levados a cabo, na sua larga maioria, pelas populações indígenas, sob o controlo e a supervisão técnica do exército (HIRT 2010; OREJAS et al. 2012). Assim, vinculamos a provável presença militar romana no Alto da Cerca com a exploração económica dos recursos minerais auríferos da vertente Oriental da serra da Padrela, inaugurando uma nova forma de ocupação e exploração do território.

\section{AGRADECIMENTOS}

João Fonte agradece à Fundação para a Ciência e a Tecnologia (FCT) a bolsa individual (SFRH/ BD/65143/2009) concedida. Queremos agradecer ao Grupo de Investigação "Síncrisis. Investigación en Formas Culturais" da Universidade de Santiago de Compostela (GI-1919) e ao seu coordenador Marco V. García Quintela a ajuda prestada na aquisição das fotografias aéreas históricas necessárias à realização deste trabalho. Agradecemos também a Alexandre Lima e a Roberto Matías Rodríguez por nos terem acompanhado no trabalho de campo e a José Alberto Gonçalves o apoio prestado no processo de restituição fotogramétrica das fotos aéreas históricas. Por último, ao senhor Maurício da Eira Laje por todo o auxílio prestado na identificação dos canais hidráulicos de Tresminas; bem haja por todo o seu interesse e conhecimento relativamente ao Património Cultural de Curros que gentilmente acedeu a partilhar connosco!

\section{BIBLIOGRAFIA}

AlMEIDA, C.A.F. 1973. Aspectos da mineração romana de ouro em Jales e Trêsminas (Trás-os-Montes). In: XII Congreso Nacional de Arqueologia (1971, Jaén), Zaragoza, Seminario de Arqueología: 553-562.

BATATA, C. 2009. Resultados das escavações arqueológicas de 2007 e 2008 realizadas no Complexo Mineiro Romano de Trêsminas e Jales. Revista Aquae Flaviae, 41: 417-431.

BatATA, C. 2011. Novos dados sobre o Complexo Mineiro Romano de Trêsminas e Jales. In: J. MATAPerelló, L. TORró I ABAT \& M. Fuentes-Prieto (Eds.), Actas del $V$ Congreso Internacional sobre Minería y Metalurgia Históricas en el Sudoeste Europeo (León - 2008), Libro en homenage a Claude Domergue, Lleida, SEDPGYM: 481-490.

BatatA, C. 2013. O Complexo Mineiro Romano de Tresminas e Jales. In: Arqueologia em Portugal. 150 anos, Lisboa, Associação dos Arqueólogos Portugueses: 785-792.

CAAMAÑO-GESTO, J.M. 1984. Excavaciones en el campamento romano de Cidadela (Sobrado dos Monxes, Coruña). Memoria preliminar de la campaña de 1981 Noticiario Arqueológico Hispánico, 18: 233-254.

CaAmaño-Gesto, J.M. 1997. Sondeos arqueológicos en la muralla del campamento romano de Cidadela. $G a-$ llaecia, 16: 265-284.

CARrocera-FernándeZ, E. 1990. El castro de San Isidro: informe de las excavaciones arqueológicas 1986. Excavaciones Arqueológicas en Asturias 1983-86. 157-162.

CARROCERA-FERNÁNDEZ, E. 1992. Excavaciones arqueológicas en el occidente de Asturias: (campañas de 1987-1990). Excavaciones Arqueológicas en Asturias 1987-90: 129-136.

Carretero-Vaquero, S.; Romero-Carnicero, M.V. \& MARTÍNEZ-GARCÍA, A.B. 1999. Las estructuras defensivas del campamento del Ala II Flavia en Petavonium (Rosinos de Vidriales, Zamora). In: II Congreso de Arqueología Peninsular, 4: 183-194.

Conrad, O.; Bechtel, B.; Bock, M.; Dietrich, H.; FisCHER, E.; GERLITZ, L.; WeHBERG, J.; WichmanN, V. \& BÖHNER, J. 2015. System for Automated Geoscientific Analyses (SAGA) v. 2.1.4. Geoscientific Model Development, 8: 19912007. doi:10.5194/gmd-8-1991-2015

Costa-García, J. 2013. Arqueología de los asentamientos militares Romanos en la Hispania Altoimperial (27 a.C. - 280 d.C.). Tese de Doutoramento, Universidade de Santiago de Compostela. http:// hdl.handle.net/10347/8857

COSTA-GARCíA, J. 2015. Asentamientos militares romanos en el Norte Peninsular: aportes de la fotografía aérea histórica, la fotografía satelital y el LiDAR aéreo. Férvedes, 8: 35-44. 
Costa-García, J.; Blanco-Rotea, R.; Gago-Mariño, M. \& FONTE, J. (2015). Novedades sobre la presencia del ejército romano en el occidente galaico. In: J. CAMINO-Mayor, E. Peralta-Labrador \& J.F. TORRES-MARTínez (Eds.), Las Guerras AsturCántabras, Gijón, KRK Ediciones: 285-289.

DAVIES, J.L. \& JoneS, R.H. 2006. Roman Camps in Wales and the Marches. Cardiff, University of Wales Press.

Del Olmo Martín, J. 1995. Arqueología aérea en tres núcleos campamentales romanos de Zamora y León. Brigecio, 4-5: 109-118.

DidiERJEAN, F. 2008. Camps militaires romains et archéologie aérienne: méthodologie et données nouvelles. Saldvie, 8: 95-115.

Didierjean, F.; Morillo-Cerdán, Á. \& Petit-Aupert, C. 2014. Traces de guerres, traces de paix armée: l'apport de quatre campagnes de prospection aérienne dans le nord de l'Espagne. In: F. CADIOU \& M. NAVARRO-CABALlero (Eds.), La Guerre et ses traces. Conflits et sociétés en Hispanie à l'époque de la conquête romaine (IIIe-Ier s. a.C.), Bordeaux, Ausonius Mémoires 37: 149-179.

DOMERGUE, C. 2012. Les exploitations hydrauliques romaines dans les dépôts alluviaux aurifères du NordOuest de l'Espagne: Las Medulas et le Teleno (Province de León). A propos de publications récentes. In: J.P. Bost (Ed.), L'eau: usages, risques et représentations: dans le Sud-Ouest de la Gaule et le Nord de la péninsule Ibérique, de la fin de l'âge du Fer à l'Antiquité tardive (IIe s. a.C.-VIe s. p.C.), Bordeaux, Aquitania Supplément 21: 111140.

FABIÃO, C. 2007. El ejército romano en Portugal. In: Á. MORILlo-CERDÁN (Ed.), El ejército romano en Hispania: guía arqueológica. León, Universidad de León: 113-134.

FONTE, J. 2008. Sistemas defensivos Proto-Históricos de Tras-os-Montes Ocidental (Norte de Portugal). Cuadernos de Estudios Gallegos, 55: 9-29. doi:10.3989/ceg.2008.v55.i121.36

FONTE, J. 2015. Paisagens em mudança na transição entre a Idade do Ferro e a época Romana no Alto Tâmega e Cávado. Tese de Doutoramento, Universidade de Santiago de Compostela. http:// hdl.handle.net/10347/13786

FORTES, M. 2009. A gestão da água na paisagem romana do ocidente peninsular. Tese de Doutoramento, Universidade de Santiago de Compostela. http:// hdl.handle.net/10347/2532

FreitAs, A.M. 1989. A Cerca de Ribas (Ribas - Freguesia de Argeriz - Concelho de Valpaços). Revista de Guimarães, 99: 319-367.

FreitAs, A.M. 2001. Carta Arqueológica do Concelho de Valpaços. Valpaços, Câmara Municipal de Valpaços.

Gago-Mariño, M. \& FernÁndez-Malde, A. 2015. Un posible recinto campamental romano en O Cornado (Negreira, Galicia). Nailos: Estudios Interdisciplinares de Arqueología, 2: 229-251.

GARCíA Y BELLIDO, A. 1961. El exercitus hispanicus desde Augusto a Vespasiano. Archivo Español de Arqueología, 34: 114-160.
GARCÍA-MERINO, C. 1996. Un nuevo campamento romano en la cuenca del Duero: el recinto campamental de Uxama (Soria). Archivo Español de Arqueología, 69: 269-273.

GonzÁlez-Álvarez, D., MenÉndez-Blanco, A. \& ÁlvaREZ-MARTíneZ, V. 2008. El campamento de Moyapán (Ayande, Asturias). Férvedes, 5: 363-371.

Helfert, M.; RAmminger, B. \& WAHL-Clerici, R. 2013. Underground surveying with 3D-laserscanning of the "Galeria dos Alargamentos" in the Roman gold mining district of Três Minas and Campo de Jales (Northern Portugal). In: P. ANREITER, K. BRANDStÄtter, G. GoldenberG, K. Hanke, W. LeitNer, K. Nicolussi, K. OEgGl, E. Pernicka, V. SCHAFFER, T. STÖLlner, G. TOMEdI \& P. TROPPER (Eds.), Mining in European History and its Impact on Environment and Human Societies - Proceedings for the 2nd Mining in European History Conference of the FZ HiMAT, 7-10. November 2012, Innsbruck, Innsbruck University Press: 207-214.

HIRT, A. 2010. Imperial Mines and Quarries in the Roman World: Organizational Aspects 27 BC-AD 235. Oxford, Oxford University Press.

MARTINS, C. 2012. Hidráulica mineira na época romana. In: M. Martins, I. Freitas \& M.I. del VAL VALDIVIESo (Eds.), Caminhos da Água: Paisagens e usos na longa duração, Braga, CITCEM: 105-123.

Martins, C., Carvalho, J., Almeida, F., \& Cavalheiro, A. 2011. Aplicação do Geo-radar no reconhecimento de uma estrutura no Complexo Mineiro de Três Minas, Vila Pouca de Aguiar, Vila Real. In: C. Martins, A. Bettencourt, J. Martins, \& J. Carvalho (Eds.), Povoamento e Exploração dos Recursos Mineiros na Europa Atlântica Ocidental, Braga, CITCEM/APEQ: 521-533.

MAtíAs-RodríGUEZ, R. 2006a. La Minería Aurífera Romana del Noroeste de Hispania: Ingeniería minera y gestión de las explotaciones auríferas romanas en la Sierra del Teleno (León-España). In: Nuevos Elementos de Ingeniería Romana. III Congreso de las Obras Públicas Romanas: 213-263.

MAtíAS-RodríGUEZ, R. 2006b. La Red Hidráulica de Las Médulas. Trazado e ingeniería. Estudios Bercianos, 30-31: 5-86.

MATÍAS-RoDRÍGUEZ, R. 2008. El agua en la ingeniería de la explotación minera de Las Médulas (León-España). Lancia, 7: 17-112.

MenÉndez-Blanco, A.; GonZÁlez-Álvarez, D.; ÁlvaREZ-MARTínEZ, V. \& JiMÉNEZ-CHAPARRO, J. 2011. Nuevas evidencias de la presencia militar romana en el extremo occidental de la Cordillera Cantábrica. Gallaecia, 30: 145-165.

MENÉndeZ-Blanco, A., JimÉnEZ-Chaparro, J., GONZÁLeZ-Álvarez, D., \& Álvarez-Martínez, V. 2012. La conquista romana del Occidente Cantábrico: novedades arqueológicas. In: Actas das IV Jornadas de Jovens em Investigação Arqueológica (JIA 2011), 2, Faro, Universidade do Algarve, Promontoria Monográfica 16: 339-346.

MenÉndez-Blanco, A.; GonZÁlez-Álvarez, D.; ÁlvaREZ-MARTÍNEZ, V. \& JIMÉNEZ-CHAPARRO, J. 2013a. Campamentos romanos de campaña en el Occidente de Asturias. In: Excavaciones Arqueológicas en Asturias 2007-2012, Oviedo, Consejería de 
Educación, Cultura y Deporte del Principado de Asturias, Dirección General de Patrimonio Cultural: 245-251.

MenÉndez-Blanco, A.; GonZÁlez-Álvarez, D.; ÁlvaREZ-MARTíneZ, V. \& JIMÉNEZ-CHAPARRO, J. 2013b. Propuestas de prospección de bajo coste para la detección de campamentos romanos de campaña. El área occidental de la Cordillera Cantábrica como caso de estudio. Munibe (AntropologiaArkeologia), 64: 175-197.

MORILlo-CERDÁN, Á. 2002. Conquista y estrategia: el ejército romano durante el periodo augusteo y julioclaudio en la región septentrional de la Península Ibérica. In: A. MorILlo-CERDÁn (Ed.), Arqueologia Militar Romana en Hispania, Madrid, CSIC, Anejos de Gladius 5: 67-94.

MORILlo-CERDÁN, Á. 2014. Arqueologia de la conquista del Norte Peninsular. Nuevas interpretaciones sobre las campañas del 26-25 a.C. In: F. CADIOU \& M. NAVARRO-CABALlERO (Eds.), La Guerre et ses traces. Conflits et sociétés en Hispanie à l'époque de la conquête romaine (IIIe-Ier s. a.C.), Bordeaux, Ausonius Mémoires 37: 133-148.

MARÍN-SUÁREZ, C.; JORDÁ-PARDO, J.F. \& GARCÍA-GUINEA, J. 2008. Arqueometría en el castro de San Chuis (Allande, Asturias, España). Férvedes, 5: 53-62.

Monte-López, R. \& Villa-VALdÉs, Á. 2015. Una domus altoimperial en el castro de Chao Samartín: ¿quién, cómo y por qué? Férvedes, 8: 277-284.

Nunes, J.; FABIÃo, C. \& Guerra, A. 1988. O acampamento militar romano da Lomba do Canho (Arganil). Arganil, Museu Regional de Arqueologia.

Lemos, F.S. 1993. Povoamento romano de Trás-os-Montes Oriental. Tese de Doutoramento, Universidade do Minho.

LEMOS, F.S. 2004. Rede viária do conventus de Bracara Augusta: a via secundária entre o vale do Douro (Peso da Régua) e Aquae Flaviae (Chaves). In: C. Auliard \& L. Bodiou (Eds.), Au Jardin des Hespérides. Histoire, société et épigraphie des mondes anciens. Mélanges offerts à Alain Tranoy, Rennes, Presses Universitaires: 407-419.

Lemos, F.S. \& MARTins, C. 2014. Sigillatas e contextos crono-estratigráficos no âmbito da mineração antiga no Norte de Portugal. In: R. MORAIS, A. FERNÁNDEZ-FERNÁNDEZ \& M.J. SOUSA (Eds.), As produções cerâmicas de imitação na Hispania, Atas do II Congresso Internacional da SECAH - Ex Officina Hispana, 1, Porto, FLUP: 339.346.

LE-RouX, P. 1982. L'armée romaine et l'organisation des provinces ibériques d'Auguste à l'invasion de 409. Paris, Diffusion de Boccard.

LOEWINSOHN, E. 1965. Una calzada y dos campamentos romanos del Conventus Asturum. Archivo Español de Arqueología, 38: 26-43.

Lopes, A.B.; Silva, A.C.F.; Centeno, R. \& Parente, J. 1994. A estátua-estela do Marco (Vreia de Jales, Vila Pouca de Aguiar): notícia preliminar. Portugália, Nova Série, 15: 147-154.

LÓPEZ-BOAdO, B. 2005. Traçado de um aqueduto romano. In: I. RodÀ DE LlanZA (Ed.), Aqua Romana: Técnica humana e força divina, Lisboa: Museu Nacional de Arqueologia: 57-69
Orejas, A.; Sastre, I. \& Zubiaurre, E. 2012. Organización y regulación de la actividad minera hispana altoimperial. In: M.Z. PIETO, P.H. GóMES \& L.M. PlazA (Eds.), Paisajes Mineros Antiguos en la Península Ibérica: Investigaciones recientes $y$ nuevas líneas de trabajo, Madrid, UNED: 31-46

PERALTA-LABRADOR, E. 2002. Los campamentos romanos de campaña (castra aestiva): evidencias científicas y carencias académicas. Nivel Cero, 10: 49-87.

Peralta-Labrador, E. 2011. Campamentos romanos en Cantabria. Castillos de España, 161-162-163: 23 26.

Pérez-Álvarez, J.; Bascón-Arroyo, F. \& CharroLOBATO, C. 2014. Photogrammetric Usage of 195657 Usaf Aerial Photography of Spain. The Photogrammetric Record, 29(145): 108-124. doi:10.1111/ phor. 12048

REDENTOR, A. 2010. Aproximação a um esboço social da área mineira romana da serra da Padrela (Tresminas e Campo de Jales). In: C. Martins (Ed.), Mineração e povoamento na Antiguidade no Alto Trás-osMontes Ocidental, Porto, CITCEM: 121-162.

Redweik, P.; Roque, D.; Marques, A.; Matildes, R. \& MARQUES, F. 2010. Triangulating the Past: Recovering Portugal's Aerial Images Repository. Photogrammetric Engineering \& Remote Sensing, 76(9): 1007-1018. doi:10.14358/PERS.76.9.1007

RIERA, I. 2005. A hidráulica dos romanos. In: I. RODÀ DE Llanza (Ed.), Aqua Romana: Técnica humana e força divina, Lisboa, Museu Nacional de Arqueologia: 41-55.

Rodríguez Colmenero, A. \& Ferrer Sierra, S. (Eds.) 2006. Excavaciones arqueológicas en Aquis Querquennis. Actuaciones en el campamento romano (1975-2005). Lugo, Unión Fenosa-Grupo Arqueolóxico Larouco-Universidade de Santiago de Compostela-Fundación Aquae Querquennae-Vía Nova, Anejos de Larouco 4.

SÁNCHEZ-PALENCIA, F.J. 1986. El campamento romano de Valdemeda, Manzaneda (León): ocupación militar y explotación aurífera en el NW Peninsular. Numantia, 2: 227-234.

SÁNCHEZ-PALENCIA, F.J. 2015. La zona minera de Tresminas (Vila Pouca de Aguiar). Aportaciones a partir de la fotografía aérea. Conimbriga, 54: 179-223.

SÁnchez-PAlencia, F.J. \& PÉREZ-GarcíA, L.C. 2000. La infraestrutura hidráulica: canales y depósitos. In: F.J. SÁnchez-Palencia (Ed.), Las Médulas (León). Un paisaje cultural en la Asturia Augustana, León, Instituto Leonés de Cultura: 189-207.

SÁNCHEZ-PAlENCIA, F.J. \& CURRÁs-REFoJos, B. 2015. Campamentos romanos en zonas mineras del cuadrante noroeste de la Península Ibérica. In: J. CAMINO-MAYOR, E. PERAlTA-LABRAdOR \& J.F. TORRES-MARTÍNEZ (eds.), Las Guerras AsturCántabras, Gijón, KRK Ediciones: 273-283.

SÁNCHEZ-PAlEnCIA, F.J. \& PÉREZ-GARCÍA, L.C. 2005 Minería romana de oro en las cuencas de los ríos Erges/Erjas y Bazágueda (Lusitania): la zona minera de Penamacor-Meimoa. In: Lusitanos e romanos no Nordeste da Lusitânia, Actas das 2 as jornadas de património da Beira Interior, Guarda, CEI: $267-$ 307. 
Sastre, I.; Beltrán, A. \& SÁnChez-Palencia, F.J. 2010. Ejército y comunidades locales en el Noroeste Peninsular: formas de control y relaciones de poder en torno a la minería del oro. In: J. PALAO-VICENTE (Ed.), Militares y civiles en la antigua Roma: dos mundos diferentes, dos mundos unidos: 117-134.

TeiXeIra, R. 1996. De Aquae Flaviae a Chaves. Povoamento e organização do território entre a Antiguidade e a Idade Média. Tese de Mestrado, Faculdade de Letras da Universidade do Porto.

Verhoeven, G.; Doneus, M.; Briese, C. \& Vermeulen, F. 2012. Mapping by matching: a computer visionbased approach to fast and accurate georeferencing of archaeological aerial photographs. Journal of Archaeological Science, 39: 2060-2070. doi:10.1016/j.jas.2012.02.022

VILLA-VALDÉs, Á. 2007a. Mil años de poblados fortificados en Asturias (siglos IX a. C.- II d. C.). In: J. FERNÁNDEZ-TRESGUERRES (Ed.), Astures y romanos: nuevas perspectivas, Oviedo, Real Instituto de Estudios Asturianos: 27-60.

Villa-VALdÉS, Á. 2007b. El Chao Samartín (Grandas de Salime, Asturias) y el paisaje fortificado de la Asturias protohistórica. In: L. BERROCAL-RANGEL \& P. MORET (Eds.), Paisajes fortificados de la edad del hierro. Las murallas protohistóricas de la Meseta y la vertiente atlántica en su contexto europeo, Madrid, Real Academia de la Historia-Casa de Velázquez: 190-212.

WAHL, J. 1988. Três Minas: vorbericht über die archäologischen Untersuchungen im Bereich des römischen Goldbergwerks 1986/87. Madrider Mitteilungen, 29: 221-244.

WAHL, J. 1998. Aspectos tecnológicos da indústria mineira e metalúrgica Romana de Três Minas e Campo de Jales (concelho de Vila Pouca de Aguiar). In: Actas do Seminário Museologia e Arqueologia Mineiras, Lisboa, IGM: 57-68
WAHL, J. 2003. Zur Wasserversorgung des rõmischen Goldbergbaus von Três Minas und Campo de Jales (Vila Pouca de Aguiar, Trás-os-Montes, Portugal). In: T. Stóllner, G. Kórlin, G. Steffens \& J. Cierny (Eds.), Man and Mining - Mensch und Bergbau. Studies in honour of Gerd Weisgerber on occasion of his 65th birthday, Bochum, Deutsches Bergbau Museum: 495-502.

WAHL-ClericI, R. 2013. Três Minas: A discussion of some aspects of the evidence for the use of water in mining. In: P. ANREITEr, K. BRANDSTÄtTER, G. GoldenberG, K. Hanke, W. Leitner, K. NicoLussi, K. Oeggl, E. Pernicka, V. Schaffer, T. StÖllner, G. TOMEdI \& P. Tropper (Eds.), Mining in European History and its Impact on Environment and Human Societies - Proceedings for the 2nd Mining in European History Conference of the FZ HiMAT, 7-10. November 2012, Innsbruck, Innsbruck University Press: 39-46.

WAHL-Clerici, R.; Helfert, M. \& WieCHOWSKI, A. 2012. Três Minas - Eine Bergwerkskatastrophe mit Rettungsaktion in der römischen Kaiserzeit. Frankfurter Elektronische Rundschau Zur Altertumskunde, 17: 12-28.

Welfare, H. \& Swan, V.G. 1995. Roman Camps in England. The Field Archaeology. London, Royal Comission of the Historical Monuments of England.

WESSELING, P. 1735. Vetera Romanorum itineraria, sive Antonini Augusti itinerarium, cum integris Jos. Simleri, Hieron Suritae, et And. Schotti notis. Itinerarium hierosolymitanum; et Hieroclis grammatici synecdemus. Curante Petro Wesslingo qui et suas addidit adnotationes. Amsterdam, Wetstenium \& G. Smith.

Wilson, A. 2002. Machines, Power and the Ancient Economy. Journal of Roman Studies, 92, 1-32. doi: $10.2307 / 3184857$ 